ARCHIVO ESPAÑOL DE ARTE, LXXXII, 328

OCTUBRE-DICIEMBRE 2009, pp. 367-392

ISSN: 0004-0428

\title{
MÁRMOLES Y ROCAS ORNAMENTALES EN LA DECORACIÓN DEL PALACIO REAL DE MADRID*
}

\author{
POR \\ M. ${ }^{\mathrm{a}}$ LuISA TÁRRAGA BALDÓ \\ Instituto de Historia, CCHS, CSIC
}

En este trabajo se pone de manifiesto el carácter eminentemente nacional que, por iniciativa de los Borbones, se quiso dar a la decoración lapídea del Palacio y que supuso el reconocimiento y la explotación exhaustiva de las canteras nacionales en el s. XVIII, la búsqueda de marmolistas que llevasen a cabo esta ornamentación, la creación y organización del real taller de mármoles, en donde se trabajó esta decoración, tanto para el Palacio como para otros Sitios Reales e incluso para edificios religiosos y de particulares.

Se desvelan, entre otros aspectos, el primer proyecto de "casamiento de mármoles" ideado por el arquitecto Juan Bautista Saqueti, para decorar el Palacio, hasta ahora inédito; la procedencia y variedad de los materiales elegidos, así como los criterios que primaron en su elección y aplicación, obedeciendo y satisfaciendo los deseos reales.

Palabras clave: Palacio Real de Madrid; Ornamentación lapídea; Mármoles; Canteras españolas; Juan Bautista Saqueti.

The author demonstrates the eminently national character of the marble decorations of the Madrid Royal Palace, resulting from the personal initiative of the Bourbons. This meant the reconnaissance and exhaustive exploitation of national quarries during the $18^{\text {th }}$ century, as well as the search for marble masons to execute this ornamentation. It was also necessary to create and organize the Royal Marble Workshop, in which much of the work was carried out, not only for the Madrid Palace but also for other Palaces in the Reales Sitios, religious buildings and even private individuals. Other aspects here disclosed include the first, unpublished project for the Casamiento de Mármoles (matching of marbles) devised by the architect Juan Bautista Saqueti to decorate the Palace, the origin and variety of the chosen materials and the criteria followed in this selection. All was put into practice obeying and satisfying royal desires.

Key words: Madrid Royal Palace; Stone ornamentation; Marble; Spanish quarries; Juan Bautista Saqueti.

* El presente trabajo constituye parte de los resultados del Proyecto de Investigación "Los pavimentos marmóreos del Palacio Real de Madrid" HUM2006-06665, subvencionado por la Secretaría de Estado del Ministerio de Ciencia e Innovación dentro de los Planes Nacionales de I+D. 
Al incendiarse en 1734 el Alcázar de Madrid, residencia hasta entonces de los Reyes de España, el rey Felipe V inició la construcción de un nuevo Palacio Real, el cual marcó un hito en la Historia del Arte Español. En lo que se refiere, concretamente, a la ornamentación lapídea de su interior, supuso el empleo de innumerables mármoles y rocas ornamentales, cuya elección obedeció tanto a la decisión de los reyes, como al parecer de los diversos artistas a su servicio: escultores, arquitectos, pintores, marmolistas... De forma que, se puede afirmar la existencia de tres periodos de máximo esplendor en el empleo de rocas ornamentales en el patrimonio artístico español: el correspondiente a Hispania Romana, el segundo coincidiendo con la construcción del Monasterio de El Escorial en el siglo XVI y el tercero de ellos con la ornamentación del nuevo Palacio Real de Madrid, en el siglo XVIII.

En la elección de materiales pétreos para el nuevo Palacio primó tanto la belleza de su colorido, como lo infrecuente o raro de ellos, sin olvidar su calidad, abundancia y la distancia en que se hallaban las canteras. El mármol y las rocas ornamentales fueron materiales preferentes tanto para su decoración escultórica, como para la ornamentación interior de las distintas habitaciones del piso principal o piso noble. Su aplicación enriqueció y embelleció estas estancias, consiguiendo darles mayor nobleza y magnificencia y contribuyendo, a su vez, al prestigio de la monarquía.

Hemos de señalar que, casi recién iniciado el reinado de Felipe V, nos encontramos con las primeras noticias que ponen de manifiesto el gusto de la monarquía por las rocas ornamentales, si bien, obedecía a un proyecto iniciado bajo el rey Carlos II. Se trataba de remodelar la vieja capilla del Alcázar, colocando en ella un nuevo retablo, así como de proceder a dotarla de nuevo pavimento. Sin embargo, la elección y características del nuevo retablo caen dentro del gusto por los mármoles y jaspes en la ornamentación que, de forma continuada desde la dominación romana, vuelve a su mayor auge en el siglo XVIII.

En 1701 había que habilitar y renovar el Alcázar, "sede y corazón de la monarquía" para el nuevo rey Felipe V. Bottineau ${ }^{1}$ nos señala que María Luisa de Saboya, en carta fechada el 5 de julio a Madame Royale, le decía: "Voy a hermosear un poco mi palacio, es decir aquello que pueda hacerse sin grandes gastos." A ello responde, concretamente, las transformaciones o hermoseamiento de la Real Capilla. El referido autor nos informa que en 1701 se hizo un desembolso de 1.500 rs. para el nuevo retablo², "que había sido traído de Nápoles por el sobrestante Felipe Papis, ayudado por Francisco Buchini, Aniel Bullurmini y Gaetano Saco" del cual, dice, ignoramos desgraciadamente, los detalles ornamentales aunque en líneas generales se componía de dos amplias calles laterales y de una central en la que se hallaba el tabernáculo encuadrado por dos nichos y que estaba enriquecido con "porfirio (pórfido) y bronce dorado." La noticia tiene gran interés no sólo en cuanto supone la confirmación del gusto regio, sino también, por lo que encierra de novedad.

Este retablo para la Real Capilla fue enviado por el Virrey de Nápoles y de la Regia Cámara, el Duque de Medina Sidonia. El citado Duque, mayordomo mayor de Carlos II, se preocupó del mobiliario que iba a necesitar Felipe V, antes de que el nuevo rey llegase a Madrid. Junto al interés del material en que fue construido, se añade el hecho de que con el retablo llegaron, también, a Madrid marmolistas italianos que deben hacerse cargo de sentar el retablo.

En el archivo del Palacio Real hemos logrado conocer algunos nuevos pormenores referidos a esta obra y los nombres de los oficiales marmolistas que con este motivo se desplazaron hasta Madrid, pues previamente a su envío se hicieron varias consultas a la Corte Española, a fin de conocer la disponibilidad de artífices expertos en nuestro país que pudiesen llevar a cabo su

${ }^{1}$ Bottineau, Yves: El arte cortesano en la España de Felipe V. Madrid. Fundación Universitaria Española, 1986, p. 301.

2 Ibidem., p. 300. A. Simancas. T.M.C. 3673 y 223 cuentas de 1701. 
montaje. El marqués de Villafranca, el 4 de abril de 1701, informa que: “... en vista de lo que S. Magd. ordena diré a V.S. que habiéndome informado si había aquí personas que puedan sentar el retablo sin la asistencia de los oficiales de Nápoles, me ha dicho Phe. Sánchez, que no halla dificultad alguna en ello; Armándole primero en el suelo en pieza que no sea humd. ${ }^{a}$ los que le han traydo de aquel reyno, para que se vea si le falta algo y la forma en que está, y que hecho este reconocimiento se puede asentar en siendo ocasión con oficiales de acá; con q según este informe parece que hecha la diligencia de armarle (como he dho.) se podrán despedir los oficiales que le han traído; puesto que no habrá dificultad en ponerle después en la Capilla cuando sea su tpo..."”.

El retablo llegó al puerto de Alicante y allí se le entregó al Gobernador de dicha ciudad quien, a su vez, lo entrega a D. Juan Ramírez, que fue la persona elegida para su traslado hasta Madrid. Los marmolistas que habían viajado con la citada obra desde Nápoles, hicieron también su viaje desde Alicante a la Corte con dicho Ramírez.

Otros escritos nos desvelan los gastos o problemas de este traslado, pues fechado en el Buen Retiro el 9 de abril de 1701, hallamos que Juan Ramírez de Arellano "pide se le manden pagar 5.216 rs. que dice alcanza de los gastos de conducción del Retablo p. ${ }^{a}$ la Real capilla desde Alicante a esta Corte."

Con Decreto de 9 de abril, el rey remitió el memorial de Juan Ramírez de Arellano y la cuenta de lo recibido y gastado en la conducción, para que fuese informado, todo lo cual se envió al Contralor, quien redujo su importe de 5.016 reales y medio que pedía Arellano a 1.605 Rs. y medio, diciendo la forma de satisfacérsele sin desembolso de la Real Hacienda: "dándole la cesión que expresa en la ciudad de Murcia, en que refiere está combenido el mismo Juan Ramírez; y así lo pongo en noticia de V.Magd...”. Esta noticia, sin firma, está fechada el 12 de julio de 1701. Ese mismo día, el marqués de Villafranca hace referencia a que "En vista del memorial y cuenta que V.Mgd. se sirvió remitirme de Juan Ramírez de Arellano de los gastos que hizo en conducir el retablo de la Rl. Capilla desde Alicante a Madrid representa a V. Mag. lo que se le ofrece. La respuesta se indica al margen: 'Como os parece'." Desconocemos en qué consistió la concesión otorgada al referido Arellano en Murcia por este trabajo.

Los oficiales marmolistas que vinieron desde Nápoles con el retablo fueron designados por el propio Duque de Medinasidonia. Los elegidos fueron: Gaetano Saco, Francisco Pucini o Buchine, Anielo Guillelmini o Aniel Bullormine.

También pasó con este motivo a la Corte de Madrid Phelipe Papis. La documentación hallada nos informa que "por sus intereses y fines particulares, obtuvo del dicho Virrey permiso de embarcarse con título de "sobrecargo", pero una queja de sus compañeros nos desvela que el dicho Phelipe Papis, que había representado a S.M. ser "sobre maestro y sobrestante de dho. Retablo siendo eso incierto, pues el dho Phelipe no es Maestro ni oficial ni ha trabajado en dho retablo no siendo de su facultad y profesión como se puede con la experiencia afirmar, y no es justo que no siendo tal se despache por superior y cabo de los suplicantes y que hayan de ser mandados de quien no entiende la facultad... y piden que la merced, que V.Mgd le ha hecho de 28 rs. cada día no se entienda concedida como cabo maestro de dicho retablo que es justo y así lo esperan..."

Nuevo dato para identificar la autoría del referido retablo nos lo proporciona otro documento fechado el 30 de julio de 1701, pues al informarnos de la presencia también en Madrid de otro marmolista italiano: Nicolas Conforto, se indica: “... que vino de Nápoles con los que trujeron el Altar de Pórfido y Bronces que envió el Virrey para la Capilla del Rl Palacio, por ser cuñado

\footnotetext{
3 A.G.P. Sección Administrativa. Leg. ${ }^{\circ}$ 1134. Año 1700.

4 A.G.P. Sección Administrativa. Leg. ${ }^{\text {. }} 1134$.
} 
del Maestro que le hizo", y continúa: "y respecto de haberle entregado otros oficiales a quienes está señalada por V.Mag. asistencia para su sustento mientras se detuvieren en esta Corte, no ha tenido que hacer Nicolas Conforto, aunque ha pretendido se le emplease en la composición del Altar y señalase estipendio como a los otros" 5 .

Los jornales concedidos fueron: al maestro sobrestante 18 rs. al día y a cada uno de los tres oficiales que vinieron para este mismo fin, 12 rs. "para mantenerse, por estar fuera de sus casas librándoseles este importe por la presidencia de Hacienda y corriendo su cobranza y paga por mano del mro. de la Cámara".

Pero la venida de Conforto a Madrid y el haber estado en esta Corte desde que llegó el retablo y no habérsele dado cosa alguna, hace que el 25 de julio de 1701, valorando los gastos que habría tenido durante su estancia, se considere justo que el Rey ordene librarle una ayuda de costa, para pagar todas las deudas que había contraído y que se pudiese volver a su Patria. A dicha consulta se responde que se le deben librar 50 doblones y que esto se haga efectivo para que se pueda ir "porque de dilatársele volverá a empeñarse de nuevo y a molestar con sus instancias precisado de la necesidad." Era exactamente el 30 de julio de 1701.

Un escrito firmado por D. Antonio de Ubilla añade algunos otros pormenores y, esencialmente, que todos estos marmolistas han recibido su salario todo el tiempo que habían estado empleados en dicho trabajo, pero "respecto que estos oficiales no tienen ya que hacer, por haber concluido lo que les tocaba hasta armar el retablo en la Capilla, como ya está, me parece se sirva V.M. de mandar se les pague lo que se les debiere... para que se les despache luego y se puedan volver a Nápoles; y que para executar su viaje se les de una ayuda de Costa... Madrid y noviembre 25 de 1701 "'

Los documentos de archivo nos descubren que, por estos mismos años, se llevó también a cabo la pavimentación y chapado con mármoles de la Real Capilla del Alcázar. En este aspecto hemos logrado averiguar que fue Juan Sánchez Barba, que aparece designado como "Maestro Marmolista", el que se encargó de realizar este trabajo.

De este retablo de pórfido y bronce nada ha llegado hasta nosotros. Aparte del incendio ocurrido en 1734, sabemos que, con anterioridad, en 1711, la Capilla del Alcázar sufrió un incendio y, según el informe que se le encargó al arquitecto Teodoro Ardemans el 14 de julio de ese mismo año, aparte del daño que había sufrido la pintura, también los mármoles habían padecido resquebrajamientos. Por ahora, ignoramos su estructura y los elementos escultóricos y decorativos que lo adornaban.

Años después, cuando, tras el incendio del Alcázar, se inició la construcción del nuevo Palacio bajo el reinado del citado monarca, se planteó casi de forma inmediata, al elaborarse los distintos programas decorativos para el edificio, la necesidad de buscar y seleccionar, igualmente, los mármoles y piedras en que había de trabajarse la parte escultórica, así como la decoración interior. Se inician entonces las primeras exploraciones de canteras españolas, a fin de disponer de información precisa sobre diversos materiales cuando la construcción del edificio regio lo requiriese.

No cabe duda de que el mármol y las rocas ornamentales han sido siempre materiales ligados al poder, tanto por su belleza como por su carácter perdurable pero, además, el empleo de los mármoles siempre ha contribuido a la expresión del poder económico, político y social. En España, el mármol constituyó el material preferente de la escultura de Corte en el siglo XVIII, abandonándose así nuestra tradición escultórica, habitualmente ligada al empleo de la madera.

Centrándonos en el nuevo Palacio de Madrid, el interés de su utilización fue doble: con fines estatuarios y como elemento decorativo de interiores. En el caso de la escultura, si tenemos en

\footnotetext{
5 A.G.P. Sección Administrativa. Ibidem.

${ }^{6}$ A.G.P. Ibidem.
} 
cuenta que quien dirigió esta ornamentación fue un artista italiano, Giovan Domenico Olivieri, oriundo de Carrara, familiarizado con el mármol y las canteras de los Apuanos, es lógico que reclamase para aquellas obras que él había de labrar el mejor mármol estatuario: el de su ciudad natal. Por ello, cuantas veces tuvo ocasión, expuso al Rey la necesidad de que se le proporcionasen mármoles de Carrara para trabajar sus esculturas. Sobre todo, porque él siempre eligió para labrar personalmente, por su nombramiento de escultor principal del Rey, aquellas obras que habían de situarse en los lugares más vistosos o visibles del Palacio y, al elegirse el material escultórico, siempre se tuvo en cuenta la ubicación de las distintas piezas ${ }^{7}$. Fue frecuente, previo a la elección del material pétreo, conocer, igualmente, si las obras estaban destinadas a ornamentar el exterior o el interior del edificio, es decir, el lugar concreto en que debían situarse, para prever los posibles deterioros que con el tiempo los agentes atmosféricos podían ocasionar, según la calidad o características del material elegido. Se buscaron, inicialmente, con fines estatuarios, canteras próximas a Madrid: Urda, Tamajón, Colmenar de Oreja, es decir, canteras pertenecientes a las provincias de Toledo, Guadalajara y Madrid. Si bien no se prescindió por completo del de Carrara, diferentes órdenes reales precisaban que de éste sólo se había de usar después de haber comprobado que el de Macael, en la Sierra de Filabres (Almería) y el de Badajoz eran inútiles para labrar piezas de escultura ${ }^{8}$.

En este intento de abastecerse de canteras españolas se buscaba, evidentemente, evitar cuantiosos gastos a la Hacienda Real, a la vez que demoras de tiempo y los consiguientes retrasos que todo ello podía ocasionar en el ritmo de las obras.

En opinión del escultor italiano Giovan Domenico Olivieri, el mármol de Badajoz era tan bueno como el de Italia, existiendo sólo la diferencia de su grano, que en el caso de Badajoz era más grueso, pero en cuanto a solidez y blancura, dice Olivieri, apenas se encontraban diferencias. En general, tanto el de Macael (Almería), como el de Badajoz se consideran de "buena grana y que se pueden trabajar como los de Carrara" ". A la vez que las características específicas del mármol remitido de las diferentes zonas de España, se hacía preciso conocer las circunstancias que podían presentar las canteras y las condiciones de los caminos en su traslado hasta la Corte. Si repasamos las noticias halladas referentes a los de Macael, los riesgos eran mayores por la aspereza de las Sierras que había que atravesar. Estas circunstancias, y algunas otras, son las que permiten opinar a los expertos sobre las ventajas del mármol de Badajoz para la escultura, con respecto al procedente de Macael. Ello llevó a la comprobación de la calidad que ofrecían los mármoles de las canteras nacionales y que los mismos artistas responsables de la labor escultórica del Palacio, Olivieri y Castro, examinasen su color, grano, blancura, porosidad etc. e incluso ellos, personalmente, se desplazaron a las canteras, con el objeto de examinarlas, decidir y señalar de dónde se debían extraer las mejores piezas ${ }^{10}$.

Para la decoración del interior: chapado, pavimentos, chimeneas, consolas, etc., comenzó a llegar a Madrid, en el reinado de Felipe V, referencias y muestras de algunas canteras nacionales, pues se pretendía tener preparado, como ya he indicado, un muestrario con la información correspondiente, sobre el cual poder proceder a la elección en el momento que el estado de la edificación lo permitiese. En este sentido, ya el 16 de agosto de 1745, desde San Ildefonso (Segovia) D. Miguel Herrero de Ezpeleta pedía al Intendente de las obras del Palacio, Baltasar de Elgueta, la remisión del arca que contenía todas las muestras reunidas hasta entonces y que se

\footnotetext{
7 TÁrraga Baldó, M. ${ }^{a}$ Luisa: Giovan Domenico Olivieri y el taller de escultura del Palacio Real. Ed. CSIC, Patrimonio Nacional, Inst. ${ }^{\circ}$ Italiano de Cultura. Madrid 1992, vol. II.

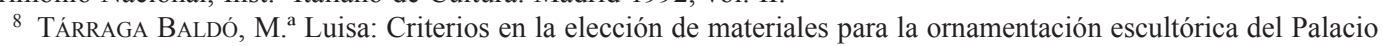
Real de Madrid. Revista ROC Maquina, n. ${ }^{\circ}$ 71, enero 2002, Bilbao, pp. 42-49.

${ }^{9}$ Ibidem, vol. II, pp. 213-266.

${ }^{10}$ Ibidem. vol. II, p. 223.
} 
guardaban y custodiaban en el Palacio del Buen Retiro ${ }^{11}$. Por estas fechas se procedía también a adornar y pavimentar el Palacio de la Granja de San Ildefonso y, posiblemente, se quisiese tener en cuenta las variedades descubiertas hasta entonces en el territorio español, para su aplicación en los pavimentos y adornos que en aquel Palacio se realizaban.

Al producirse el fallecimiento de Felipe V, en julio de 1746, correspondió a su hijo Fernando VI y a su esposa la reina María Bárbara de Braganza tomar la decisión sobre la ornamentación lapídea del nuevo Palacio. Como ésta era una labor que no sólo se consideraba costosa, sino también dilatada en su ejecución, se pide al arquitecto mayor que determine cuanto antes la elección de los materiales que para ello va a emplear y que presente los diseños a los Reyes para su aprobación y, de esta forma, que los mármoles elegidos puedan extraerse y trasladarse a la Corte, ya que todo ello requiere tiempo. Saqueti, antes de proceder a ejecutar lo que se le pide sobre esta ornamentación, consulta, el 29 de septiembre de 1746, el parecer del nuevo monarca en cuanto a la utilización y aplicación de mármoles y rocas en el interior del Palacio: desea conocer, entre otras cosas, si gustará al rey "que todas las paredes de la capilla, sean de mármoles hasta su cornisa inclusive y las bóvedas pintadas; o si sólo han de ser de mármoles, los frisos, pilastras y adornos de puertas y ventanas; y lo demás pintado, y estucado". Si "además de la capilla, querrá V.M. que se adornen de mármoles, las paredes del salón grande del cuarto de V.M. y la galería del de la reina; y si estos adornos han de ser cubriendo todas las paredes, hasta la cornisa, de forma que no haya hueco que no sea de mármol; o si querrá que se hagan de mármol los frisos, pilastras y cornisas, y los adornos de puertas, y ventanas; y que los entrepaños sean de yeso, acomodando a ellos las pinturas que V.M. eligiere, y haciendo en los mismos entrepaños algunas otras pinturas de nuevo o si sólo querrá que se hagan de mármol los frisos, y adornos de puertas, y ventanas, y todas las paredes, y cornisas queden en blanco para estucarlas, pintarlas, o cubrirlas de pinturas" y si además querría el Rey "que se pongan frisos de mármoles y adornos de puertas, y ventanas en las otras piezas públicas del cuarto del rey y del de la reina... si querrá que los suelos de la capilla, salón y galería sean de mármoles de varios colores y si gustará que se practique lo mismo en las otras piezas públicas de ambos cuartos...". Consulta también el arquitecto el parecer de los Reyes sobre si en aquellas habitaciones familiares del Rey y la Reina los suelos han de ser de mármoles o de baldosas finas "en atención a la continua asistencia, y la comodidad con que deben estar en estas piezas familiares"12.

Es tal el atractivo que suscitaban el mármol y las rocas ornamentales para los Borbones que fue decisión de Fernando VI adornar de él todas las paredes, de forma, que no hubiese un hueco que no fuese de mármol, tanto en la Capilla como el Salón de Funciones y salones grandes del cuarto del Rey y en la galería y cuarto de la Reina. Como veremos, si se renunció, en el caso de las habitaciones reales, a poner en práctica la idea de decorarlas cubriendo con mármoles sus paredes hasta la cornisa, esta decisión no obedeció a motivos de naturaleza económica, sino más bien al deseo de conseguir mayor confort, pues únicamente preocupaba que en invierno la frialdad e incluso la posible humedad que pudiesen producir fuese un inconveniente para la comodidad de los Reyes. Otra de las razones que se alegan en el caso del llamado Salón de Funciones es la de que, según la función, era preciso variar sus adornos, ya que éstos debían guardar correspondencia con cada ceremonia, lo que obligaba a mudar colgaduras, cornucopias, arañas, etc., y los mármoles de sus muros, o bien podían impedir esas variaciones o previsiblemente quedar dañados con ellas. Se acabó, pues, prefiriendo el hacer las habitaciones menos frías, aun perdiendo magnificencia y hermosura.

Una resolución fechada el 30 de septiembre de 1746 preveía, "los Adornos de Mármoles para el Palacio" y, según constancia documental, fue decisión del rey Fernando VI y de su esposa

\footnotetext{
11 A.G.P. Sección Obras de Palacio. C. ${ }^{\text {a }} 18259$ Exp. 1.

12 A.G.P. Secc. Obras de Palacio. C. 1396 Exp. 2.
} 


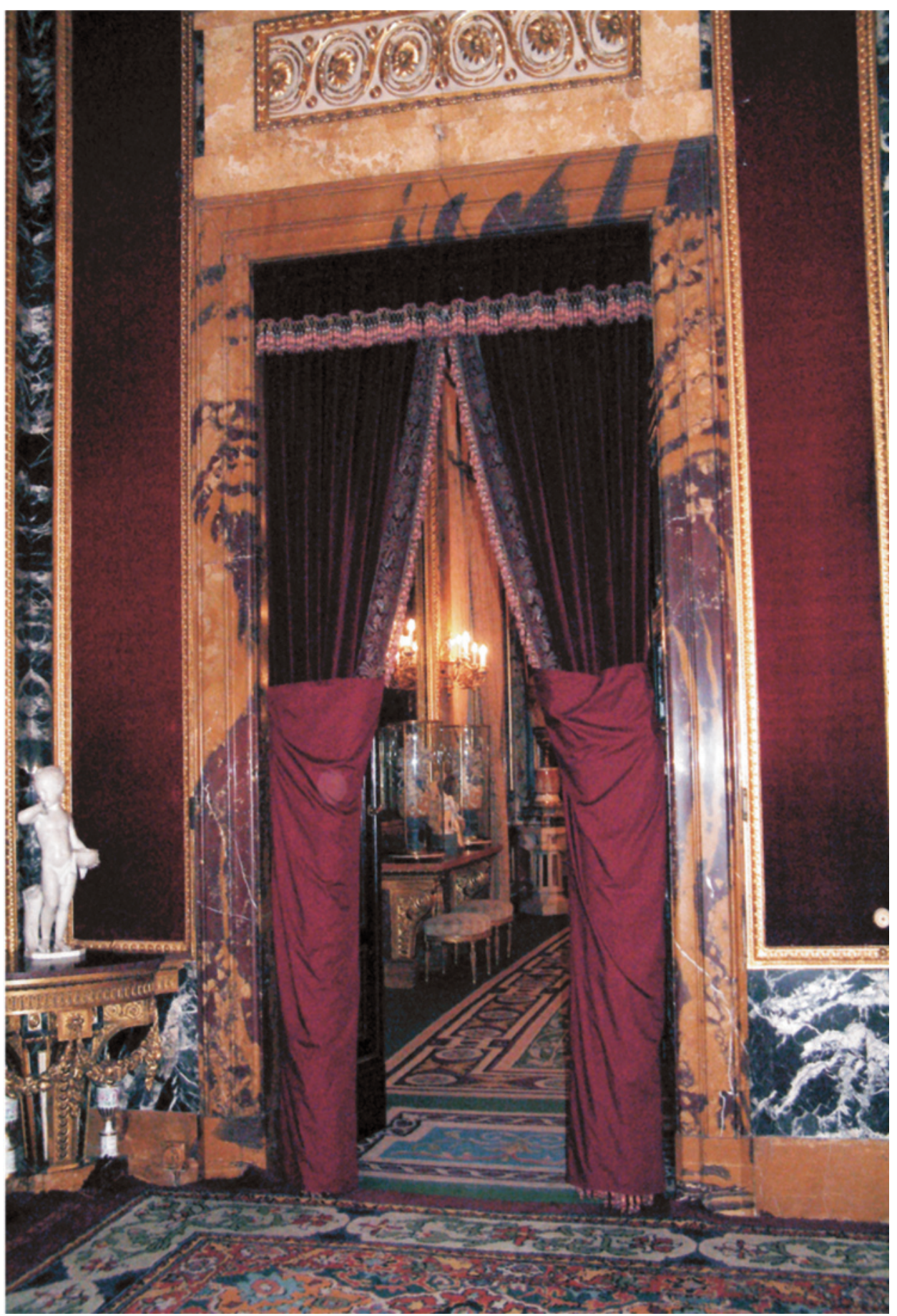

Fig. 1. Madrid. Palacio Real. Comedor de diario. 


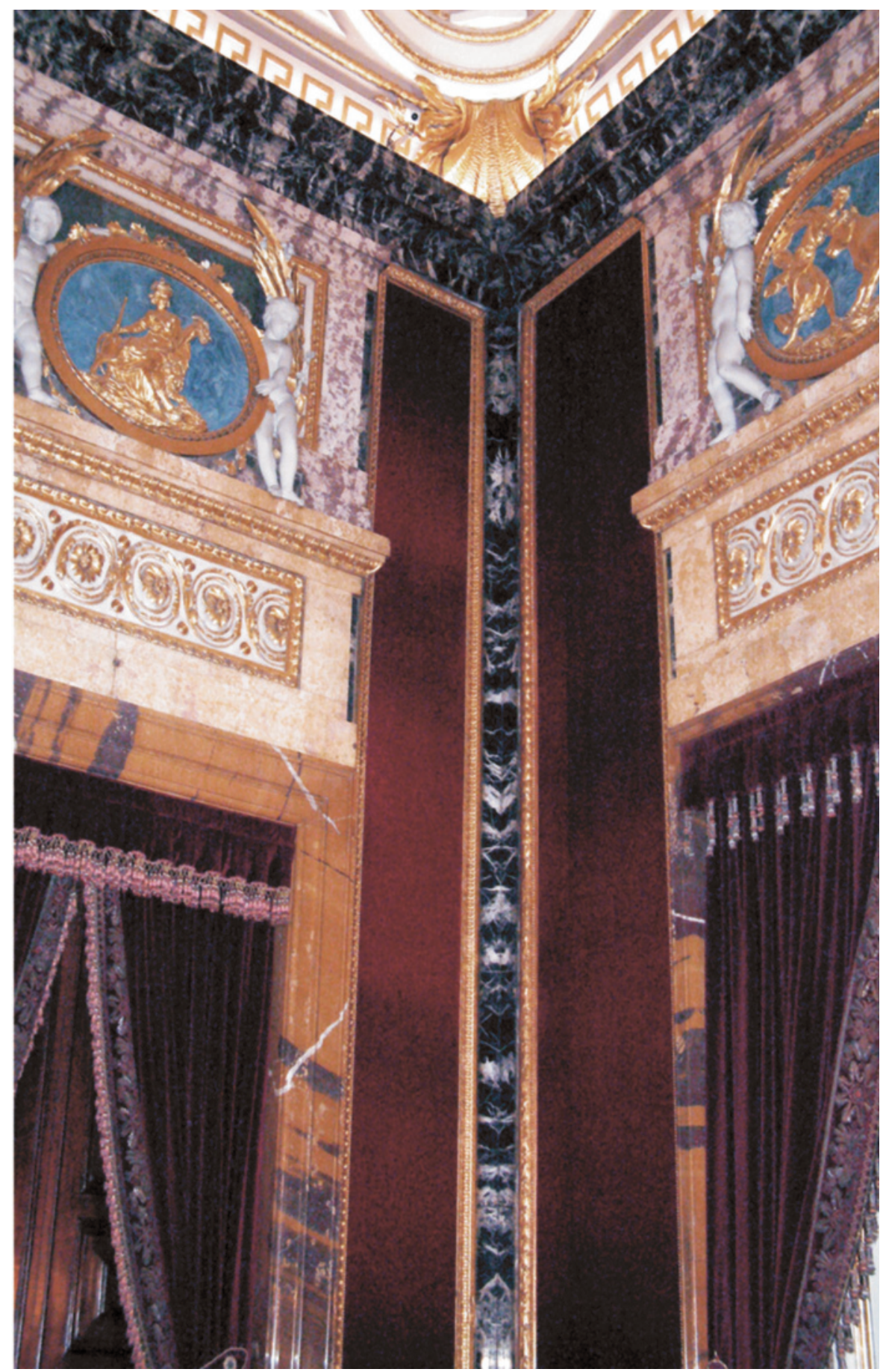

Fig. 2. Madrid. Palacio Real. Comedor de diario. 
la reina María Bárbara de Braganza el que en el nuevo Palacio Real de Madrid, concretamente, los mármoles y rocas ornamentales se emplearan en las salas y gabinetes del piso principal correspondientes a las salas públicas y en las habitaciones y otras piezas públicas destinadas a los Reyes y, muy especialmente, en la Capilla, la que deciden sea únicamente el espacio que debe solarse con mármol. Las demás estancias del Palacio fue decisión real que se pavimentasen con baldosas. De la habitaciones se revistieron algunas partes de sus muros hasta una determinada altura: arrimaderos y zócalos y, por deseo de los monarcas, se emplearon, únicamente, para resaltar y adornar elementos arquitectónicos de las diferentes habitaciones, tales como: cornisas, frisos, arquitrabes, dinteles y jambas de puertas, dejando los entrepaños de yeso, para así poder acomodar en ellos, las pinturas y tapices. También se utilizaron en columnas, chimeneas, capiteles, tableros de consolas y mesas, pedestales, marcos, relojes, etc. (figs. 1 y 2 ).

El proceso de esta ornamentación y la toma de decisiones fue largo, produciéndose durante el reinado de Fernando VI, cambios de decisiones, pero que afectaron, básicamente, más a la elección de los materiales y organización del trabajo que a su aplicación.

Con la llegada al trono de España del rey Carlos III y su nuevo arquitecto Sabatini se introdujeron modificaciones que, como veremos, afectaron, fundamentalmente, a la Capilla y en cuanto a las estancias y salones los cambios de parecer los podemos apreciar, especialmente, en los bellos pavimentos marmóreos del mismo, que en el reinado de Fernando VI habían quedado reducidos a la Capilla. De este cambio, son buenos testimonios no sólo la Saleta y Salón Gasparini, sino otra serie de gabinetes del Palacio (figs. 3, 4 y 5).

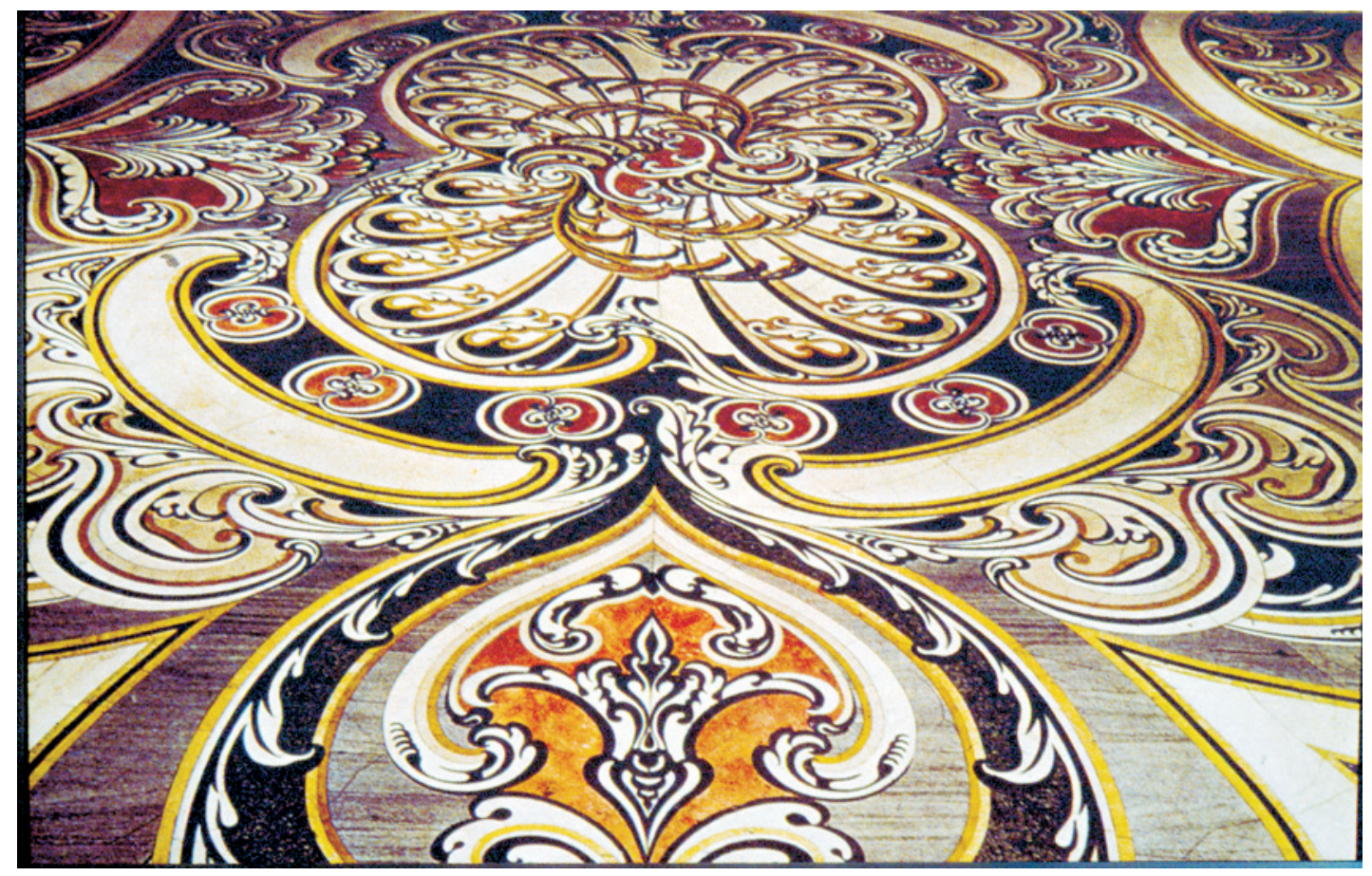

Fig. 3. Madrid. Palacio Real. Salón Gasparini. 

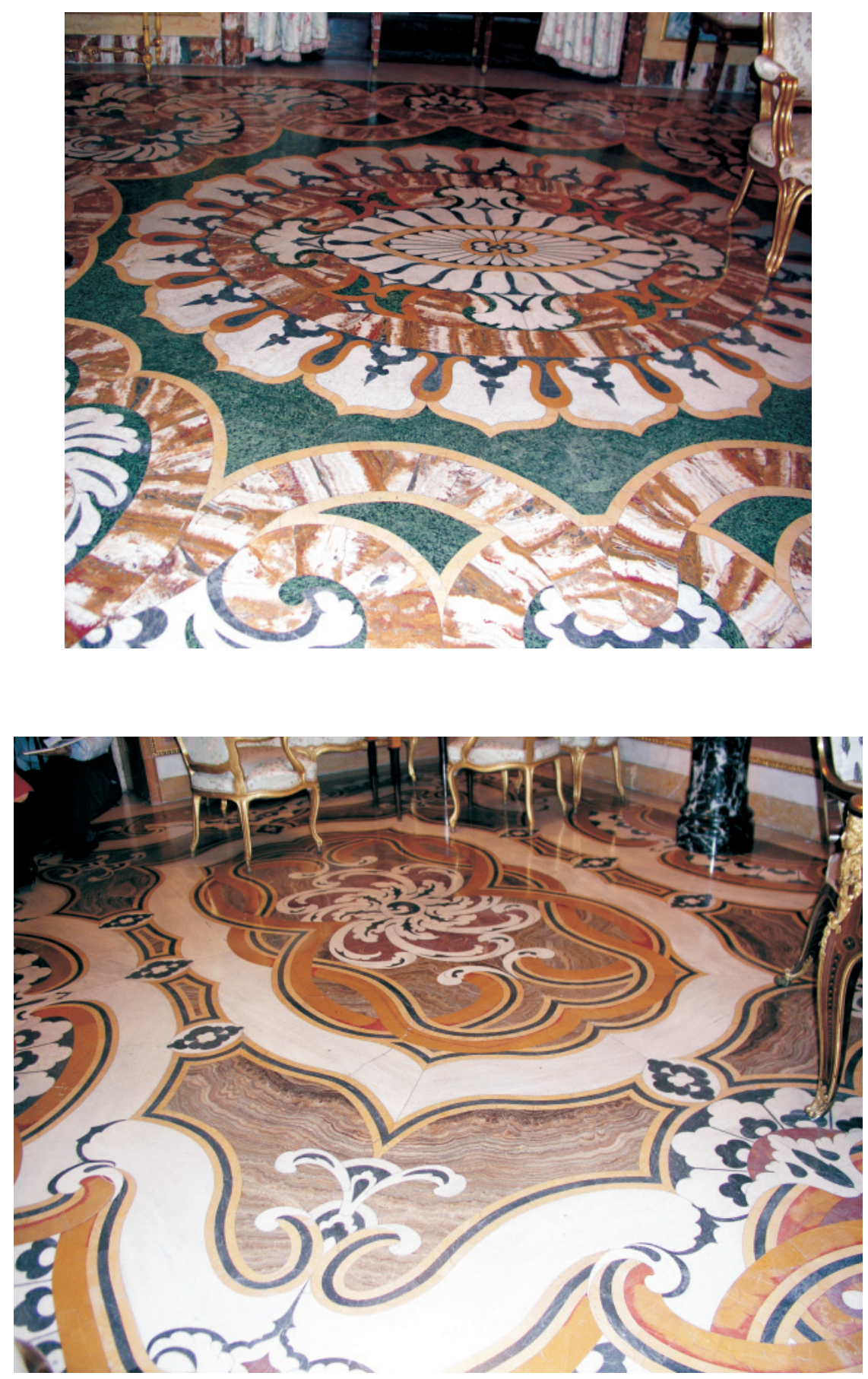

Figs. 4 y 5. Madrid. Palacio Real. Habitaciones del Rey Francisco. 
Una vez conocido el parecer real sobre qué zonas se debían decorar y qué habitaciones, se planteó de inmediato la elección de los materiales pétreos, teniendo en cuenta, aparte de otras circunstancias, su calidad, colorido, veteado, rareza, etc. En esta selección primaron no sólo razones de tipo estético, y técnico, sino también de naturaleza económica y, por supuesto, la necesidad de evitar retrasos en la construcción del edificio, razón decisiva para determinar la utilización de mármoles y rocas ornamentales de procedencia española; pero, sobre todo, lo fue aún más, el deseo de imitar el ejemplo que dos siglos antes habían dejado los lapidarios italianos en el retablo y tabernáculo de El Escorial y que ha constituido siempre un motivo de orgullo nacional. Consta que el marmolista italiano Jacome da Trezzo, al servicio de Felipe II, manifestaba, refiriéndose especialmente al tabernáculo, que todo él era "de jaspes finos y duros hallados y sacados en estos reinos de España" y así se hizo constar en la inscripción que se puso en dicho tabernáculo: "totum hispano e lapide".

Los Borbones, siguiendo estos ejemplos del reinado de Felipe II, pretendieron dar, también, un marcado carácter nacional al embellecimiento pétreo del nuevo Palacio, poniendo de manifiesto, una vez más, la rica variedad de nuestra orografía. Se quiso un Palacio para el Rey de España embellecido con mármoles y rocas de España. El escultor de cámara de Fernando VI, el gallego Felipe de Castro, entonces también desplazado a las canteras de Colmenarejo en busca de bellos materiales, opinaba en mayo de 1747, refiriéndose al tabernáculo de El Escorial como modelo a tener presente en la elección de los mármoles para ornamentar el nuevo Palacio: "debo decir a V.S. el que habiendo yo visto las piedras preciosas del tabernáculo del Escorial las que no puedo alabar con palabras, pues admira la belleza de ellas; y constándonos por la inscripción que hizo esculpir el Sr. Phelipe Segundo en el zócalo de esta maravillosa obra: el q. todas son piedras, y diásperos de España, me hace difícil se haya perdido la noticia de las canteras de adonde hayan salido, y que esta cosa no esté registrada en el archivo de aquel Rl. Monasterio"13.

Se buscó, pues, con especial interés documentación existente en los archivos que indicase la procedencia de los materiales empleados en las referidas obras. De forma especial se deseó localizar el admirable "diáspero sanguíneo" o "jaspe sanguíneo" que había sido utilizado en las ocho columnas del citado tabernáculo. Asimismo, interesó conseguir información precisa de los parajes y canteras de donde procedían los muchos y exquisitos mármoles de la Capilla de la Sagrada Forma, situada a espaldas de la sacristía del citado monasterio. Se aseguraba que en la secretaría de la Junta de Obras y Bosques tenía que haber noticias "de los parajes y canteras que produjeron dichos mármoles ${ }^{14}$ ". Se solicita de la citada Secretaría una "puntual noticia de la canteras de mármol que contiene dicha Capilla... a fin de usar de ellas para el Servicio y Adorno de la referida Real Fábrica de Palacio". Cumpliendo esta orden, el 27 de mayo de 1747, D. Manuel Santiago de Ayala, enviaba al Ministro Carvajal y Lancáster una relación con las canteras de mármol y jaspes de donde se sacaron para la obra de El Escorial.

A partir de entonces y coincidiendo, pues, con el reinado de Fernando VI se inició una explotación y reconocimiento sistemático de todas las canteras nacionales.

Esta ornamentación del Palacio fue larga y costosa, pues supuso la inversión de grandes sumas en exploraciones y descubrimientos de canteras, desplazamientos de expertos por todo el territorio nacional, contratación de marmolistas y empelechadores, la puesta en marcha de un

\footnotetext{
13 A.G.P. Sección. Obras de Palacio. Leg. ${ }^{\circ} 460$.

14 A.G.P. Sección. Obras de Palacio. C. ${ }^{\text {a }}$ 18265/11. Las noticias enviadas referentes a las columnas del tabernáculo indicaban que el 21 de octubre de 1581 otorgó Gregorio Barragán una escritura de cesión y traspaso a favor de Felipe II de una mina de jaspe colorado junto a Aracena, diócesis de Sevilla, y el Rey por ello le hizo merced de 800 ducados por una vez, por los gastos y costas que tuvo en descubrir dicha mina, y por el beneficio que pudiese tener de ella, y dio orden de que se beneficiase para una obra de su real servicio. Se añade que podían haber quedado señales o vestigios de donde se sacaron las columnas, porque eran ocho y de una pieza y de longitud tenían más de siete palmos y que también se había sacado para el retablo una porción considerable, lo cual no podía haberse hecho sin alterar la constitución de la cantera.
} 
taller para elaborar las obras y, por supuesto, requería abundante mano de obra, adecuación de caminos y puentes, disponibilidad de galeras, carretas, ganados y pastos, transportistas expertos que lograsen poner en la Corte los materiales sin graves deterioros, o pagar gastos en los fletes, cuando éstos se trasladan por mar. Asimismo, conlleva el pagar las indemnizaciones consiguientes, porque, en ocasiones, la búsqueda y excavaciones, afectaban a plantaciones o cultivos de particulares o porque al transportar los bloques a la Corte las carretas causaban graves perjuicios a su paso, concretamente, así se expone al referirse a las canteras de Colmenar de Oreja, de donde se extrajo gran cantidad de piedra ${ }^{15}$. A ello se añadía el coste de herramientas, el mantenimiento de fraguas donde aguzarlas, la necesidad de pólvora, el mantener semanas, meses e incluso años al personal comisionado para este fin; el construir casetas en donde guardar las herramientas; cercar en ocasiones, como en Espejón (Soria), las canteras, y hasta pagar un guardián para vigilar las ya abiertas y destinadas al servicio del Rey, así como los materiales y piezas extraídas y en el transporte había que facilitarles los víveres y pastos que necesitasen y aguaderos para sí y sus ganados, darles hospedaje, etc. ${ }^{16}$ Las sumas invertidas en esta ornamentación fueron incalculables, pues, además de lo ya dicho, fue necesario el poner en funcionamiento y mantener un nuevo taller: el Real Taller de Mármoles, ubicado en las proximidades del Palacio, concretamente al lado de la llamada casa del Martinete y posteriormente en el Campo del Moro, cuya trascendencia fue de suma importancia a lo largo de todo el siglo XVIII e incluso en el XIX y en el que se trabajaron los adornos para el edificio regio y para otros edificios con destino a la monarquía, así como para particulares o con destino a iglesias, como la catedral de Segovia ${ }^{17}$.

Para la exploración de estas canteras se comisionó a escultores, canteros, lapidarios, arquitectos, marmolistas, aparejadores y a todas aquellas personas de experimentada habilidad o conocedoras del lugar, con la obligación de hacer llegar muestras, ya pulidas, a la Corte y de facilitar todo tipo de noticias sobre las canteras. Para ello, previamente, se les proporcionaba el correspondiente "pasaporte de descubridor", que les habilitaba para estas búsquedas, pero que, en caso de infringir las órdenes reales, se les retiraba. Ellos fueron también los encargados de conservar las canteras descubiertas, así como las piezas que hubiesen sido extraídas, las cuales eran marcadas con las iniciales "M R" y "R": "Mármoles del Rey" y "Rey".

Con anterioridad, como ya he indicado, en el reinado de Felipe V se habían dado órdenes para el descubrimiento de las canteras y se había encargado de ello, incluso a personas particulares, con la prohibición de que ninguna pudiera usar de las tales canteras y con la obligación de traer y presentar muestras en la intendencia del Palacio, a fin de que al hacer la elección se dispusiese de referencias en cuanto a calidad, colores, dureza, abundancia y distancias de las canteras a Madrid. Sin embargo, al parecer, algunos de estas personas particulares encargadas del descubrimiento de canteras se olvidaron de su cometido y no traían a la Corte las muestras que debían, sino que incluso comercializaron algunas de las piezas sacadas, vendiéndolas, dándolas a quienes ellos querían y hasta pretendían haber adquirido un derecho personal sobre la explotación de las mismas. Por este motivo, una orden del rey Fernando VI, fechada el 17 de septiembre de 1748, resolvió que las canteras que hasta entonces se hubiesen descubierto, limpiado, abierto o escombrado con órdenes y permiso suyo y todas las que a partir de entonces se descubriesen o limpiaren "sean y se mantengan como propias y privativas de la fábrica del Real Palacio, y que ninguno de los que las han descubierto, abierto, ... usen de ellas, en todo ni en parte, aunque se les haya dado permiso o licencia y hayan presentado muestras en esta Intendencia". Por esta real orden se anulaban, a partir de entonces, todos los permisos dados hasta esa fecha. Ordenaba el

\footnotetext{
15 A.G.P. Sección. Obras de Palacio. Leg. ${ }^{\circ}$ 388. Año 1749. Se dice "destruyen el término de Panes, olivas y pastos".

16 A.G.P. Sección. Obras de Palacio. C. 18267 Exp. 7.

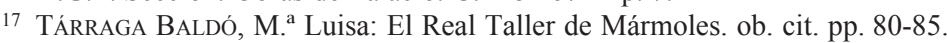


Rey, asimismo, que de ello se informase a los Corregidores y Justicias de las ciudades y villas, mandando que se procediese contra los transgresores, bien embargándoles las herramientas, los carruajes, las caballerías, e incluso poniéndolos en prisión en caso necesario.

Para que nadie pudiese alegar ignorar tales órdenes, se mandó publicar Bandos en las ciudades, correspondiendo a los Corregidores y a la Justicia el velar por su cumplimiento.

Excepcionalmente, si se pretendía sacar algunas piezas, para destinos particulares: conclusión de alguna iglesia o catedral, gradas de un altar, retablos, columnas, etc., mandaba el Rey al Intendente de las obras del Palacio que tomase los informes correspondientes de los artífices de aquella determinada obra y también que se informase si las tales piezas que se solicitaban, por el número o medidas, podían hacer falta para la obra del Palacio, y si su extracción podía perjudicar los bancos de las canteras. En caso negativo, el Intendente lo comunicaba al Rey para que éste, según el informe, pudiese consentir la extracción que se solicitaba, pero siempre debían disponer de la orden que les autorizaba a ello.

Se planteó, desde un principio, una insistente búsqueda de alabastros, jaspes, pórfidos y mármoles. En especial, se buscan las tonalidades rojas, concretamente, el tan admirado y deseado "diáspero sanguíneo". Para esta información se recurre, previamente, a los Corregidores de las Villas, quienes, a su vez, auxiliándose de escultores, arquitectos, marmolistas, canteros o personas expertas en la materia, remitieron a la Corte la información de que disponían.

Como las referencias de archivo aludían a que el "diáspero sanguíneo" de las columnas del Tabernáculo de El Escorial procedían de Aracena (Sevilla) y también, previsiblemente, de la zona de Cabo de Gata (Almería), la exploración del territorio andaluz fue exhaustiva y primordial (fig. 6).

Uno de los primeros comisionados en esta búsqueda fue el escultor malagueño Fernando Ortiz, destinado a examinar las canteras y todo el territorio de la alta y baja Andalucía hasta el Cabo de Gata; otros, como Damián García, el arquitecto Eugenio Vayas y Luis Bernasconi exploraron, informaron y se responsabilizaron de los mármoles y canteras de Castilla la Vieja; el escultor Carlos Vargas o Bargas, exploró las de Aracena (Sevilla) y, de manera especial, la descubierta por el marmolista italiano Rappa en Consuegra (Toledo), conocida como "piedra florida o alabastro oriental". En la zona de Andalucía nos encontramos con el maestro marmolista francés Juan Bautista Pirlet, concretamente en Luque, quien confiesa haber descubierto y abierto una cantera de jaspe encarnado en el sitio del Valle de dicha jurisdicción ${ }^{18}$.

También se encargó a Guillermo Bowles el reconocimiento de las canteras de jaspe de Andalucía, exactamente, la inspección y reconocimiento de las canteras de Sierra Morena, cabo de Gata, el contorno de Almería hasta Cartagena, Aracena y Pruna en el reino de Sevilla, Mérida en Extremadura y Sierra de Filabres, indicándole que en éstas se detendrá y deberá hacer un minucioso examen, a fin de formar y traer instrucciones de todas las circunstancias que hay que observar para sacar estas piedras, pues en esta sierra se halla el mármol blanco que puede servir para las estatuas del Palacio. Cuando años después, en 1787, se desplazó hasta la referida Sierra de Filabres el marmolista del rey Juan Bautista Galeotti, éste acotó para la ornamentación del Palacio la cantera llamada del Pozo, otra junto al río, en el cerro de la Fuente Maestra, ambas cercanas a Macael, otra en el cerro de Maymon, jurisdicción de Vélez Blanco (Almería) y otra en las inmediaciones de Loja (Granada).

Fueron innumerables los ocupados en explorar y descubrir las canteras. En razón de la amplitud del presente trabajo no nos es posible pormenorizar sobre ello, únicamente añadiremos que el escultor

\footnotetext{
18 A.G.P. Sección. Obras de Palacio. C. ${ }^{a} 18$ 266. Pirlet mantuvo autos judiciales, pues en 1748 dice había descubierto esta cantera hacía siete años y había conducido a la Corte diferentes piezas, pero en esta ocasión había dejado diferentes piezas labradas y otras comenzadas a descubrir y al regresar halló que otro maestro marmolista se había introducido en dicha cantera y estaba trabajando y sacando piedra. La cantera estaba en la Cañada del Valle, Sitio las Higueras, en el término de la villa de Luque (Sevilla). Se ordenó poner preso al otro marmolista y sus oficiales, a la vez que se ordena no se importune a Pirlet en la saca, bajo pena de 10.000 reales.
} 

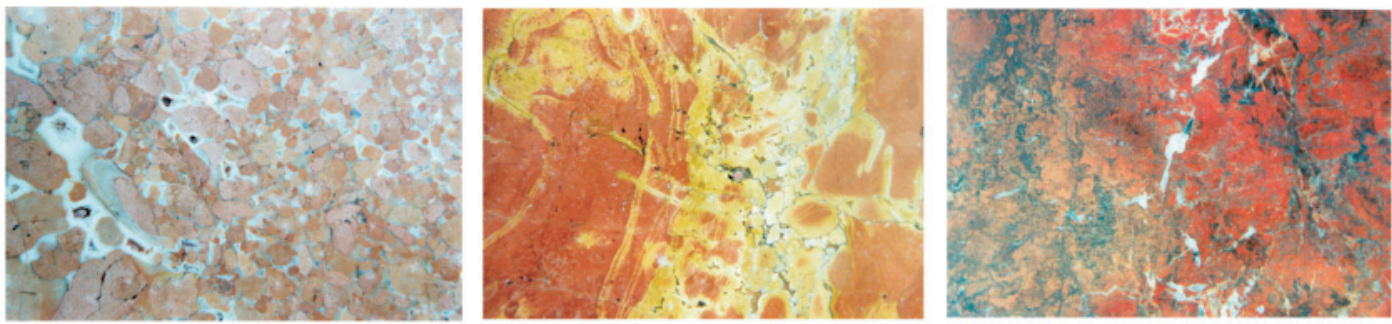

\section{CABRA (Córdoba)}

SEVILLA
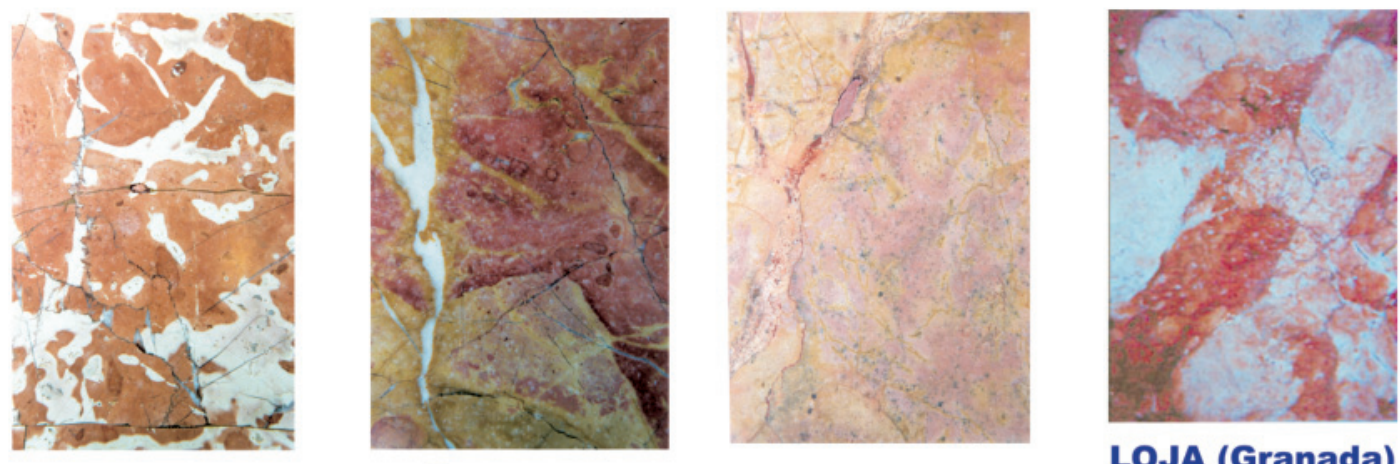

MORÓN (Sevilla)

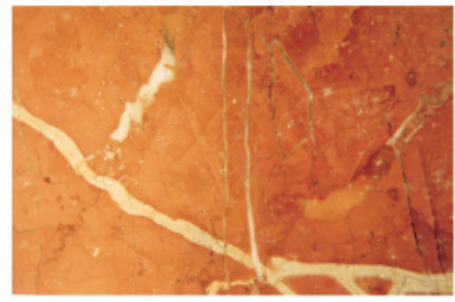

ASPE (Alicante)

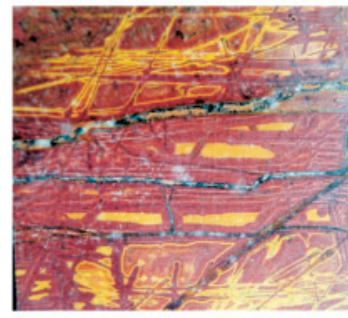

SEGAT (Valencia)
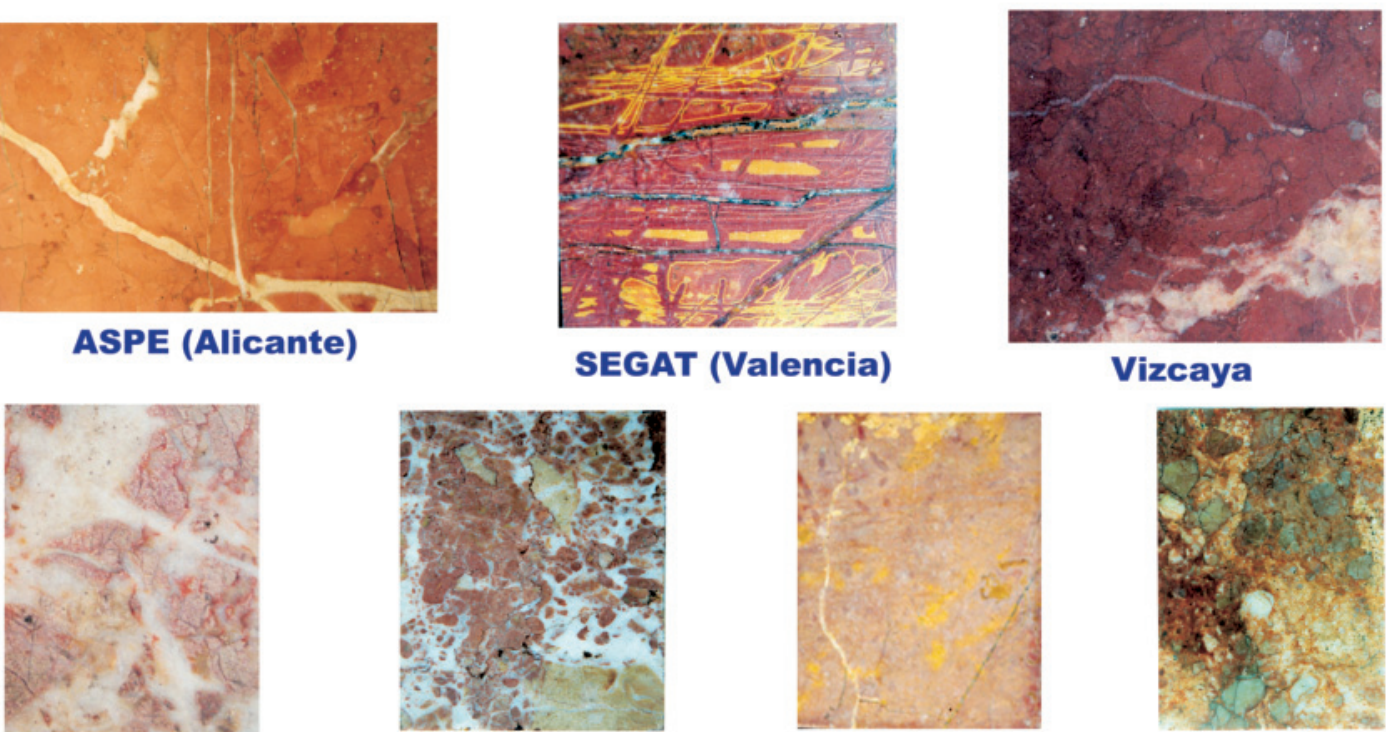

Vizcaya

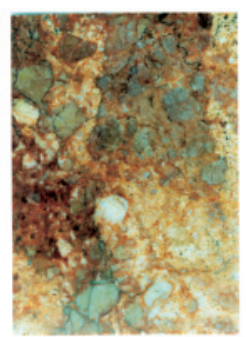

Provincia de Cuenca

Fig. 6. Muestras rojas de canteras españolas. 
Domingo Martínez se encargó de facilitar referencias sobre las canteras de Molina de Aragón; que Mateo Lagüera y otros exploraron Castilla la Nueva; que Esteban de Lasa, Manuel Sayzar y Pedro Ignacio Insaurrandiaga lo hicieron en Vizcaya; los italianos Juan Bautista Tramaca, Mateo Betoli, Carlos Bernasconi y los hermanos franceses Pirlet, también se emplearon en estas tareas y contribuyeron a facilitar informaciones al respecto arquitectos como: Pedro Juan de la Viesca, maestro mayor de los Reales Alcázares de Sevilla y el arquitecto de la catedral, aparte de hacerlos otros muchos en Aragón, León, Cuenca, Murcia, Valencia, Alicante, Cataluña, Asturias, Madrid, los Pirineos, etc.

A lo largo del reinado de Fernando VI se ampliaron las noticias sobre las distintas canteras españolas que había iniciado su padre Felipe V. Debemos también al Rey Fernando VI, el que comisionase al irlandés Guillermo Bowles para facilitar información sobre canteras españolas, si bien, no pudo acabar esta tarea por motivos de salud. Posteriormente, en el reinado de Carlos III, son los propios marmolistas italianos Nicolás Rappa, Domingo Galeotti y su hijo Juan Bautista Galeotti quienes prosiguieron en este cometido hasta su fallecimiento y recorrieron y exploraron todo el territorio nacional, ampliando y completando la información que hasta entonces se disponía sobre canteras de España y dando cierto rigor científico a sus exploraciones, descubrimientos e informes. Ellos mismos harán nuevos descubrimientos de canteras en nuestro país. De hecho, si en tiempos de Felipe V se disponía en la intendencia de la obra de Palacio de un arca con muestras y algunas otras sueltas sobre las que poder elegir, al finalizar el siglo XVIII son numerosas las arcas y muestrarios que se hallan en la intendencia de Palacio, de forma que se contó con una amplia colección de lapidarios, fruto del interés de nuestros Reyes y de las distintas expediciones hasta entonces costeadas, para conseguir la más completa información de nuestra riqueza orográfica.

El interés por nuestros materiales pétreos se extendió en estos años fuera de nuestras fronteras, remitiéndose desde Bilbao, concretamente en 1766, a través del Príncipe de Masserano, nuestro embajador en Londres, un total de 37 muestras procedentes de las canteras de Mañaria (Vizcaya), Villamayor, Socuéllamo y Pedro Muñoz en la Mancha, Náquera y Museros en el reino de Valencia, mármol blanco de Badajoz, de Macael, Lanjarón, Tortosa, Jaca, lugar de Hecho, Urda, reino de León, cercanías de Aracena en Sevilla y de canteras pertenecientes a los obispados de Cuenca y Córdoba y en estas mismas fechas se plantea su comercialización en Inglaterra, exactamente, de las canteras de Tortosa, Granada y Málaga, estableciéndose en 1768 la normativa y derechos que "habían de pagar por extracción de piedra los extranjeros y particulares". También hay testimonios documentales de cómo eran apreciados en Italia algunos de nuestros materiales, enviándose a ciudades como Roma y Génova. Interés similar despiertan ciertas variedades en Francia, a donde se enviaron muestras solicitadas a través de nuestra representación diplomática.

Se consiguió, pues, bajo Fernando VI, Carlos III y su hijo Carlos IV reunir una colección de lapidarios que comprendía todos los puntos y variedades de nuestra geografía. Parte de estas colecciones pasaron al Gabinete de Historia Natural, fundación de Carlos III, actualmente Museo Nacional de Ciencias Naturales, otras fueron regaladas, como la colección Lorenzana. La catedral de Segovia conserva, también, una pequeña colección correspondiente al retablo mayor, y algunas otras que, esperamos dar a conocer en breve.

A partir de las primeras muestras reunidas contenidas en un arca y algunas otras muestras sueltas, se encargó al arquitecto Saqueti que procediese a elaborar el proyecto de "Casamiento de Mármoles para el Palacio".

La tardanza de Saqueti en cumplir este cometido no sólo inquieta a los Reyes, sino que irrita y preocupa al Ministro Carvajal y Lancáster, hasta tal punto que el 11 de mayo de 1747 dirige un escrito al Intendente Elgueta en estos términos: "Estreche V.S al Arquitecto m. ${ }^{\circ} r$ para que luego acabe y me envie la elección de Mármoles, que le está encargada para la Capilla y Cuartos Reales de Palacio"19.

\footnotetext{
19 A.G.P. Sección Obras de Palacio C. ${ }^{\text {a }}$ 18.259/1.
} 
La falta de cumplimiento a esta petición por parte de Saqueti obliga al ministro Carvajal a darle un ultimátum. Era, exactamente, el 29 de febrero de 1748. Había transcurrido casi un año desde la última petición de este Proyecto hecha por el Ministro. Su disgusto por el incumplimiento de Saqueti queda bien manifiesto en el escrito que en la citada fecha dirige al Intendente, en el que le dice: "Ha muchos días, que al Arquitecto mayor está encargada la elección de los Mármoles, que se han de emplear en los adornos de la Fabrica de Palacio. Y estrañado el Rey, que hasta ahora nada se ha adelantado en esto; que los Artífices se desconsuelan, y se van, o perecen, y que no es disimulable el defecto de aver de repetir una misma orden, quando el que la ha de cumplir no está legítimamente ocupado: manda S.M., que V.S. diga al Arquitecto mayor, que el Rey absolutamente quiere que la elección de Mármoles esté hecha, y comunicada a S.M. para el día 20 de Marzo, que empieza a correr mañana y si en todo el dho día 20 de Marzo no la hubiere pasado a manos de V.S... quiere S.M. que en aquella misma noche me participe V.S., que ya quedan en la Intendencia todas las Muestras de Mármol recogido... Y también quiere, y estrechamente manda Su Majestad a V.S., que sin esperar nueva orden, ni aviso, el día 21 cite V.S. a la Intendencia al mismo Arquitecto Mayor y a los Escultores Olivieri, Castro, Dumandre y Boiston, que teniendo presentes los dibujos y plantas, y ordenes tocantes a esto, empiecen a hacer la elección de Mármoles y continuen todos los días hasta fenecerla...”. Es más, añade Carvajal, que si Saqueti se presentase el primer día, se le advierta que ha de asistir todos los demás hasta su conclusión y que si faltase algún día no le llame el Intendente, sino que en su lugar nombre a los arquitectos Lezen y Tami y al primer delineador Ventura Rodríguez, y que entre todos ellos decidan la elección, para que el 14 de abril él pueda tener el Proyecto en sus manos con la firma de todos los que hayan intervenido ${ }^{20}$.

Saqueti se disculpa argumentando que, aunque hace días que se le encargó, él ha tenido que poner en grande la planta y perfiles de la Capilla y esta tarea requiere tiempo. Es más, si la fecha límite de su entrega la establecía Carvajal el 20 de marzo, Saqueti presentó su primer "Proyecto de Elección y Casamiento de Mármoles para el Palacio" el día 18, el cual fue remitido a Fernando VI el expresado día 20. El Proyecto se le devuelve a Saqueti unos días después, indicando que en él, el arquitecto no ha especificado el número de piezas que precisa de los colores elegidos, como tampoco sus dimensiones, sin cuyos datos es imposible proceder a su encargo, ni tampoco conocer el presupuesto que habrá que invertir. A fin de que complete estas deficiencias se le da un plazo de dos meses. Es más, se le advierte que si precisa de ayuda se le den las personas que él eligiere o necesitase para que trabajen bajo su dirección solamente en ello.

La elección y casamiento de mármoles ideada por Saqueti en 1748 fue hecha ateniéndose a las muestras disponibles hasta entonces: un arca con veinte muestras todas ellas numeradas y, aparte, algunas muestras sueltas que se distinguían con letras. En total, algo más de 62.

Las muestras que se le envían sabemos que tres procedían de Morón, y eran encarnadas, y blancas y encarnadas las otras dos, pero de rojo más subido una que otra; otras dos eran de Saceda de Trasierra en la provincia de Cuenca. De ellas se dice que una es de tono "encarnadino". Otras dos eran de la cercanía de Hernani: una de ellas "color negro con pintas blancas" y la otra de color "encarnado oscuro con pintas blancas"; otra procedía de Macael (Almería) y era blanca. El resto correspondían a canteras de Granada, color de mezcla; de Museros, de distintos colores; de Novelda y Cartagena. De esta última, se señala era "color de pórfido"; otra era de los Vélez (Almería), además de otra de las cercanías de Jaca de "distintos colores" y, por último, otra "de junto a Almería", pero que no se indica su color ${ }^{21}$.

Según expone el arquitecto, en su elección ha obviado determinadas muestras de las que figuraban en el arca y no había querido aplicarlas, pues las reservaba a los altares y tabernáculo de la

\footnotetext{
20 A.G.P. Ibidem.

21 A.G.P. Sección. Ob. de Palacio. Ibidem.
} 
Capilla. Sin duda, por su mayor vistosidad o rareza de colorido. Señala, asimismo, que las muestras con los números $1,6,9,15,16,17,18,22,32,40,50,51,54$ y 62 , cuya procedencia, por el momento, desconocemos, no había hecho uso de ellas por no considerarlas de buena calidad.

Según el casamiento de mármoles y jaspes que presentó el arquitecto a los Reyes, hasta ahora inédito ${ }^{22}$, observamos: en primer lugar, que en éste no se incluía la Capilla, según expone, por estar pendiente de varias resoluciones; en segundo lugar, que los materiales elegidos corresponden a canteras diversas de España, pero hay un marcado gusto por rocas de determinada procedencia, concretamente por los pajizos de Saceda, los verdes de Granada, los negros y blancos de San Pablo de los Montes, azulados blancos y agatados de León, los amarillos o pajizos y blancos con vetas encarnadas de Alcadrete, y las diversas variedades de San Jerónimo de Espeja o el encarnado bajo con vetas agatadas de Náquera, aparte de elegir los de Tortosa, Borja, Pamplona, Tudela, Lérida, Villamayor, Sigüenza y alguno de Albortón; que en las consideradas habitaciones y piezas públicas del Rey, en el adorno de puertas, ventanas, jambas, dinteles, cornisas etc. hay una preferencia o inclinación por las tonalidades denominadas pajizas o color amarillo, de diversa procedencia. Los elegidos corresponden, concretamente, a canteras de Saceda de Trasierra, distante de la Corte unas 13 leguas. De este lugar se eligieron los jaspes pajizos, aunque, también se seleccionaron de allí otras variedades descritas como: el "color de melocotón", "el almendrado", el "encarnado claro" y "encarnado con manchas blancas". Según esta elección se prevé utilizar con profusión el de las canteras de San Jerónimo de Espeja y el llamado mármol de Espejón, en sus distintas variedades: pajizo, pajizo con vetas moradas y morado con manchas amarillas distantes las canteras 30 leguas de Madrid (fig. 7).

Dentro de esta preferencia por las tonalidades amarillas fue elegido, asimismo, el "pajizo con manchas blancas" procedente de Borja a 50 leguas de Madrid; el de "color caña con manchas negras" de Tudela a 40 leguas; los pajizos y amarillos de Alcadrete o Alcaudete a 18 leguas. Completando y casando estas tonalidades doradas se eligió el negro o negro y blanco de San Pablo de los Montes (Toledo), distante 16 leguas; el verde de Granada, o el encarnado con vetas blancas de Lérida. Por el contrario, al seleccionar el arquitecto los destinados a las habitaciones de la Reina, se inclina, preferentemente, por emplear más los tonos rojizos, bien el encarnado, y encarnados con vetas blancas de Saceda, blancos con vetas encarnadas de Alcadrete, el encarnado bajo con vetas agatadas de Náquera, el encarnado almendrado de Villamayor y el jaspe blanco y encarnado de Pamplona, sin olvidar algunas otras variedades procedentes de Tortosa, León, Granada y, por supuesto, no podían faltar los procedentes de Espejón y San Jerónimo de Espeja. De los blancos el preferido fue el de Macael.

Se le achaca al arquitecto el que no ha dado las medidas de cada una de las piezas ni ha presentado los dibujos con los colores de las rocas elegidas, de forma que los Reyes puedan comprobar de manera más clara la propuesta que se les hace, antes de aprobarla.

En junio de 1749 aún se seguían esperando que el arquitecto concluyese los dibujos que se le pedían, como asimismo, que al presentar el nuevo Proyecto tuviese en cuenta las muchas muestras que nuevamente habían sido descubiertas y que, según Saqueti, él no había visto. El 29 de julio se insiste en que se le repita "seriamente concluya los casamentos de mármoles, sobre lo que estoy cansado de hablarle...". Se quería saber la elección definitiva, teniendo en cuenta las nuevas muestras, así como las medidas y el ornamento que debía llevar el Salón de Funciones, todo lo cual se tiene previsto enviarlo a París y Roma, "para que se hiciesen dibujos por los mejores artífices de cada cosa" y el Rey pudiese decidir. Por estas mismas fechas es interesante destacar que el Rey ordenó que el Proyecto presentado por Saqueti se pusiese a disposición de los escultores Giovanni Domenico Olivieri y Felipe de Castro, para que lo examinasen a la mayor brevedad, diesen su parecer y presentaran dibujos. Curiosamente la orden indica "se mande al

\footnotetext{
${ }^{22}$ A.G.P. Sección Ob. de Palacio C. 18267 Exp. 7.
} 


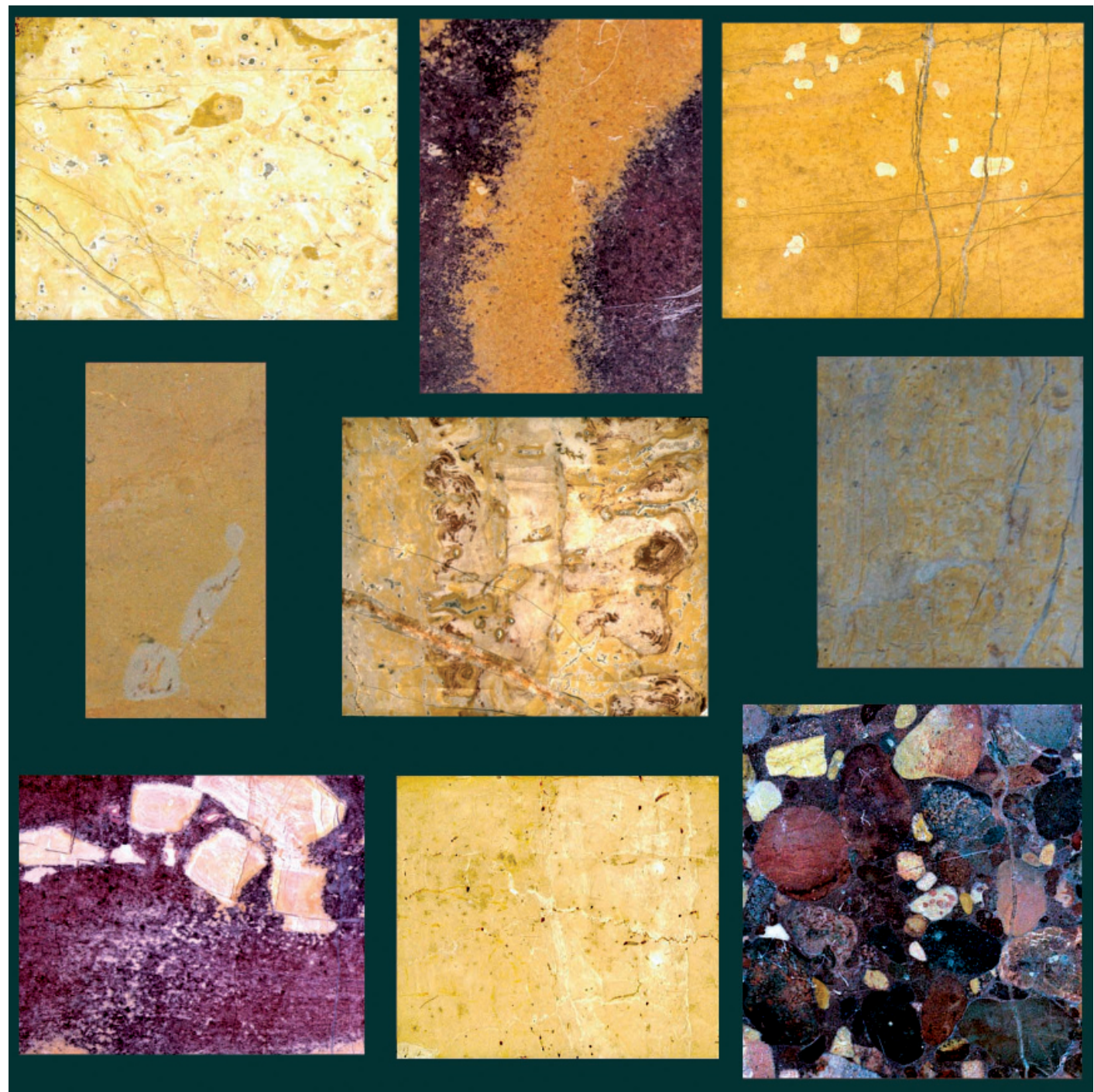

Fig. 7. Variedades de Espejón.

primero y avise al $2 .^{\circ}$ que se dediquen a esta tarea". No se era ajeno al dar la orden del carácter del escultor gallego. En el plazo de quince días el Rey quería disponer de este dictamen.

En la misma fecha se ordenó a Vanloo que hiciese un dibujo del adorno más adecuado para el Salón de Funciones, pidiendo al Intendente y a Saqueti todas las noticias e instrucciones que necesitase para ello. Esta misma orden se le transmitió, igualmente, al pintor Amiconi.

Saqueti enviará su nuevo Proyecto con fecha 3 de agosto de 1749, teniendo en cuenta las nuevas variedades de muestras descubiertas -el cual transcribimos en documento adjunto-, pero indicando que no incluye la Capilla, sino sólo las habitaciones del piso principal, ya que estaba pendiente de las resoluciones que los Reyes tomaran sobre ella, en función de las ideas que él ya les había presentado. Saqueti, al presentar este nuevo Proyecto dice que ha hecho la elección teniendo en cuenta el mayor beneficio económico en la proximidad de las canteras, pero añade: "sin faltar al adaptamiento de la Arquitectura y Hermosura y grandeza de su vista". 
Las demoras sufridas hasta entonces y la previsible duración de esta ornamentación, aparte de su cuantioso gasto, plantea la necesidad de elegir un "Jefe subalterno de profesión marmolista de los mejores, que dependiendo del arquitecto mayor en cuanto a las medidas, dibujos y modelos lleve a cabo esta labores, para abreviar su ejecución porque si esto se encarga a Saqueti será eterno". Se considera necesario implicar también en esta tarea a marmolistas y tallistas, encargándoles la ejecución de dibujos de chimeneas, puertas, ventanas, etc. y que éstos se pasen a la Academia, para que allí se elijan los mejores y después decidan los Reyes. También en estas fechas se propone la creación de un taller en donde se ejecuten estos trabajos. Se observa, asimismo, que en el Proyecto de Saqueti nada se dice sobre los suelos del Palacio y aunque, inicialmente, no se tuviese previsto que todos ellos fuesen de mármoles, sino solamente algunos y los demás de baldosas, era preciso conocer, también, los colores elegidos y procedencia del material, para planificar, igualmente, la saca, labra y transporte de todos ellos e incluso la necesidad de establecer varias sierras de agua que permitiesen la ejecución de los pavimentos.

Entre los elegidos para hacer los dibujos de chimeneas, puertas, etc., fue uno de ellos el escultor Felipe de Castro, el cual no estuvo dispuesto a realizar este trabajo, por considerarlo correspondía al arquitecto y no a él y así se lo hizo saber al Intendente el 30 de diciembre de $1749^{23}$.

Como observamos, el deseo del mejor acierto en la ornamentación lapídea del Palacio Real de Madrid obligó, una y otra vez, a su revisión y a contar con el parecer de los mejores artífices al servicio del Rey. Se lleva la consulta a la Junta de arquitectos y escultores para, conociendo el parecer de todos ellos, proceder a su elección definitiva y ejecución. En principio lo primordial era determinar los mármoles para la Capilla Real.

El 13 de mayo de 1750, reunida la citada Junta de obras, eligieron para las 16 columnas de la Capilla las muestras procedentes de Espeja y Sigüenza y que las seis columnas que debían ir en el cancel de la Capilla fuesen de color verde claro de las canteras de Granada. La elección definitiva se deja a los Reyes; pero, tal y como comunica el ministro de Estado, Carvajal y Lancáster, el 15 de mayo de 1750, "no les han gustado a los Reyes las Piedras de Espeja, y de cerca de Sigüenza", de aquí que fue preciso pensar en otras variedades. Los Reyes pidieron al arquitecto un diseño de la Capilla, en donde apareciesen figurados los distintos colores de las piedras que eligiesen y, asimismo, el número de la muestra correspondiente para poder apreciar más fácilmente el resultado final que con la propuesta se iba a conseguir y así, con mejor conocimiento, podían proceder a la elección. Igualmente se procedió en 1750 a hacer un modelo de la Capilla, que se trabajó en la casa de Saqueti24

Las propuestas se sucedieron a lo largo de varios años. Así a mediados de 1753, reunida, una vez más, con el muestrario delante ${ }^{25}$, la Junta presentó nueva propuesta. Se prefirió, entonces para las columnas de su interior el negro veteado de blanco de Mañaria, que es el que en la actualidad vemos en la Capilla (fig. 8). Para el friso se había seleccionado el negro veteado de blanco de Vizcaya, semejante a las columnas, aunque con mayor predominio de blanco. De estas mismas canteras sería el elegido para el zócalo, aunque se pide que tenga mayor predominio de negro que blanco. El arquitrabe y cornisa se decidió fuese amarillo procedente de Espejón. Pero la idea, tal

23 Dice Castro a Baltasar de Elgueta: “... haviendo visto la adjunta Relación de Dn Juan Saqueti que V.S. me remite p. $^{\text {a }}$ que pr ella haga (como el Rey quiere y S.E. le previene) los dibujos de Arquitectura para el adorno delas Piezas publicas del quarto principal del nuevo R1. Palacio se la buelbo a remitir a V.S. para que V.S. informe a S.E. que todo lo que se me pide es cosa de Arquitectura, que mejor que otro alguno lo hará Dn. Juan Saqueti, que crio la fabrica y tendrá, ya estudiadas sus partes asi exteriores como interiores, save que alto, ancho y profundo tienen las ventanas, puertas, chemineas y los demas adornos necesarios al complemento de la Arquitectura que tiene echa; de todo lo qual caresco io de noticias, y no puedo con fundamento dar cumplimiento a lo que V.S. me pide...".

24 A.G.P. Sección de Obras C. ${ }^{\text {a }} 1221$.

${ }^{25}$ Ya en julio de 1753 el muestrario de mármoles había aumentado a dos cajas, que fue preciso trasladar desde el Buen Retiro y contar con ocho hombres y dos angarillas para su traslado. 


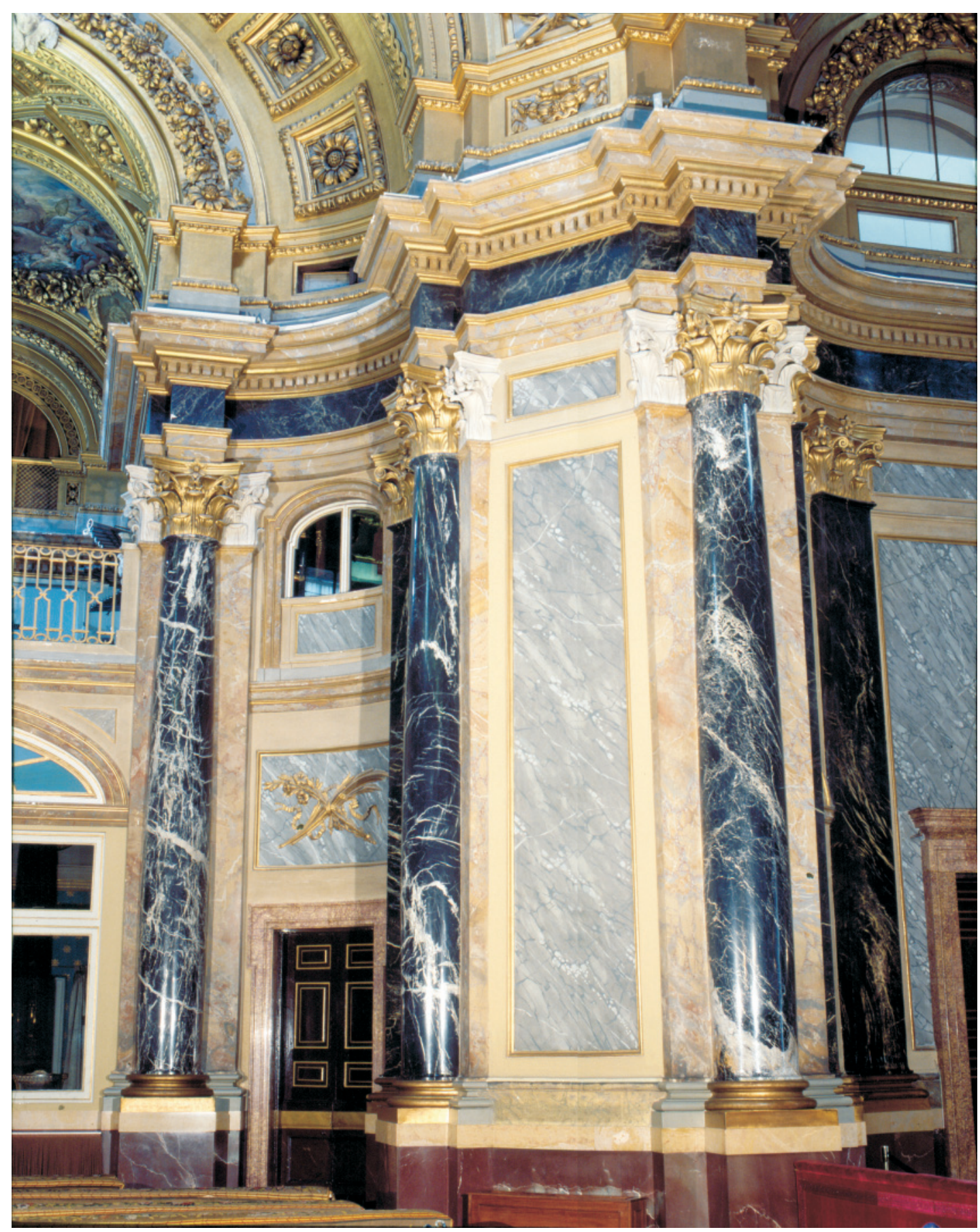

Fig. 8. Madrid. Palacio Real. Capilla. 
y como veremos, no fue respetada en su conjunto, aunque sí el colorido, por lo cual la variación se hace difícil advertirla a simple vista.

Años más tarde, concretamente en 1757, la Junta de Obras compuesta por el pintor Giaquinto los dos escultores, y cuatro arquitectos, aparte de intendente, tesorero, etc., elegía el 17 de marzo otros jaspes y mármoles de los dominios de España que se debían emplear en la Capilla, teniendo en cuenta tres arcas de muestras.

En esta ocasión se seleccionaron para ella los verdes y "blancos con manchas color de canela" de Granada, los pajizos de Espeja, "el encarnado con vetas pajizas" de Cabra, el "encarnado con vetas blancas" de Pamplona, el brocatello de Tortosa, el de "manchas encarnadas oscura y con manchas color de caña" de Málaga, el verde esmeralda y hasta un total de otras cinco variedades de la Sierra de Molina de Aragón, más otros dos: uno agatado, de la Serranía de Mijas y otro de tonos amarillos procedente de Cuenca. La razón de esta nueva elección responde, sin duda, al adorno de otros elementos arquitectónicos de la Capilla, como jambas y dinteles de puertas, rodapiés, zócalos, mesa de altar mayor y laterales, etc.

En relación con la Capilla y los materiales empleados en arquitrabe friso y cornisa no queremos dejar de aclarar que, aunque, inicialmente, se quiso cumplir la decisión real de emplear los materiales procedentes de Espejón y Vizcaya en arquitrabe, friso y cornisa y se enviaron las plantillas con las medidas correspondientes; conocemos quienes fueron los responsables de hace la saca ${ }^{26}$ : se extrajeron todas las piezas necesarias. Además de existir noticias pormenorizadas de la continua llegada de las carretas con este material, de su coste y pagos e incluso hay testimonios evidentes de su llegada a la fábrica del Palacio certificada por el arquitecto Juan Tamy; sin embargo, hemos podido averiguar que Saqueti se queja en varias ocasiones del mármol de Espejón y por varias razones. Así en agosto de 1757 dice que las piezas de amarillo aparte de no responder a las medidas pedidas y ser irregulares "tiende a desportillarse" por sus pelos y pide que se advierta esto a los sacadores para que salgan limpias y también que se les advierta tengan cuidado los conductores al cargarlas y descargarlas ${ }^{27}$. De nuevo, el 6 de octubre de 1757, Saqueti vuelve a quejarse que de las 28 piezas llegadas ese mes y que estaban destinadas a la primera hilada de la cornisa, sólo sirve una, pues las demás vienen muy manchadas de color morado y tampoco traen la medida que se ha pedido correspondiente al alto y, si su grueso se pedía de 20 dedos, se habían traído de doce, además de tener vetas y pelos, por todo lo cual eran inservibles ${ }^{28}$. En esta situación, se llegó a pensar en emplear el pajizo de Cuenca.

Asimismo, con respecto a las columnas verdes de Granada que se extraen con destino al cancel en abril de 1759, tampoco se colocaron. Llegaron, igualmente a la Corte, pero aparte de haberse quebrado alguna de ellas, sus medidas también resultaron inadecuadas. De forma, que en la Capilla, para la cual, desde un principio, se pensó en un revestimiento de mármoles exquisitos, acabó siendo sustituido el mármol, a excepción de las columnas, mesas de altar, zócalos, jambas y dinteles de puertas, etc., por el estuco, si bien respetando el colorido de los mármoles que habían sido elegidos, por lo que como ya he indicado el cambio no se observa a primera vista.

Con idea de completar la decoración lapídea del Palacio durante todos estos años fueron muchos los adornos de chimenea adquiridos, como también lo fueron infinidad de mesas y tableros de mesas de diversas variedades, los que se compraron por parte de la Hacienda Real y que entraron en los almacenes a lo largo de estos años, para hacer uso de ellas según se fuesen necesitando.

En este sentido y con el deseo de elegir para la Capilla los materiales más bellos, es curiosa una noticia de archivo de principios de 1756 que nos da a conocer cómo los escultores del Rey,

\footnotetext{
${ }^{26}$ Fueron a lo largo de estos años los aparejadores Damián García, sustituido posteriormente por Eugenio Vayas y asimismo el escultor italiano Pedro Martinengo, entre otros.

27 A.G.P. Sección Obras de Palacio C. ${ }^{\text {a }} 18261$.

${ }^{28}$ A.G.P. Sección Administrativa C. ${ }^{a} 1418$.
} 
Olivieri y Castro, conjuntamente con el arquitecto Ventura Rodríguez, examinaron una mesa que había sido puesta en venta, cuyo tablero es descrito por Olivieri como de "diáspero oriental florido" y por Castro y Ventura Rodríguez, como "diáspero oriental, cuyo color es sobre campo helado transparente, manchas rojas medianas, y pequeñas, contorneadas y entretejidas de venas blancas y en algunas partes mezclado el rojo con pajizo...", pues bien, tan bella pieza, después de haber sido valorada por los referidos artistas, se adquirió con la finalidad de utilizar su tablero en el tabernáculo o en el retablo de la Capilla, pues ambas obras se dice habían de hacerse "de los jaspes más exquisitos que se puedan hallar..." 29 .

En estas fechas y bajo el reinado de Fernando VI, teniendo presente, fundamentalmente, las labores de marmolistería previstas para la Real Capilla del Palacio, la Junta de Obras del Palacio expuso al Rey la necesidad de escribir a Roma o Florencia, para que a través de nuestras Embajadas y Ministros, se buscasen dos maestros marmolistas "escarpelinos o empelechadores" que dirigiesen esta decoración, así como las de otras salas del edifício regio. Se indica, incluso, las características que debían reunir ambos sujetos: ser de habilidad más sobresaliente en empelechar; contar con la aprobación de los artistas pensionados por el Rey en la Academia de San Lucas de Roma: los escultores Vergara y Gutiérrez, el arquitecto Miguel Fernández y el pintor Preciado de la Vega. Se añade, además, que tengan "robustez, edad joven y con sanidad". Esta petición se hizo desde Aranjuez, en la primavera de 1758, a través de un escrito que el Conde de Valdeparaiso dirigió a D. Alfonso Clemente de Aróstegui, manifestándole los deseos del Rey de buscar en Roma dos Profesores diestros "en obras de impelichatura", añadiendo que "a lo menos uno tenga algún gusto de diseño, con práctica en obras de mosaico.... ofreciéndoles lo que parezca a V.S. correspondiente... y obligándolos, si puede conseguirse, a que tenga cada uno dos discípulos españoles"30.

Alfonso Clemente de Aróstegui, consiguió dos hábiles escarpelinos: Nicolás Rapa y Domingo Galeotti, residentes en Roma, a quienes contrató bajo las cláusulas de que recibirían cada uno 500 escudos por una vez, para costearse el viaje, y otros mil escudos romanos de sueldo al año cada uno y vivienda. La admisión de ambos, al haber fallecido Fernando VI, correspondió al rey Carlos III, quien dio la conformidad de su venida y la aceptación de lo pactado y quiso que por el tesorero de la real negociación del Giro en la Corte de Roma, se les entregasen los 500 escudos de ayuda de costa a cada uno, para que luego se pusiesen en camino, asegurándoles que se les pagarían los mil escudos de sueldo acordados, desde el día que justificaren haberse puesto en marcha. La noticia fue comunicada por el Marqués de Squilace al Sr. Nicolás de Francia desde el Buen Retiro el 2 de febrero de 1760. Ambos llegaron a Madrid a mediados de 1760, de forma que tanto su llegada a España y la puesta en marcha del Real Taller de Mármoles se correspondan con un nuevo reinado y un nuevo arquitecto: el de Carlos III y su arquitecto Francisco Sabatini.

Aparte de la llegada al trono del nuevo monarca, no conviene olvidar que las sucesivas variaciones que se produjeron en los proyectos decorativos para el Palacio se repitieron también en el llamado "Casamiento de Mármoles" de su interior. A ello hay que sumar los cambios que, obligadamente, se produjeron por inconvenientes en conseguir el tamaño de las piezas o la imposibilidad de hallar todas las que se precisaban o lograr en ellas determinadas vetas, tal y como presentaba el colorido o manchas de las muestras, además del cambio de parecer y de gusto de nuestros propios monarcas. Todo lo cual obliga a abandonar algunas ideas inicialmente previstas. Pero no hay duda de que en el Palacio, en general, se respetó las resoluciones tomadas por Fernando VI, en cuanto a la aplicación de los mármoles, a excepción de sus pavimentos, que debemos a la decisión de Carlos III, pues de las baldosas decididas para ellos por su antecesor en el trono, las estancias se cubrieron con bellos pavimentos marmóreos y, fundamentalmente,

29 A.G.P. Sección. Obras de Palacio. C. ${ }^{\text {a }} 9$.

30 TÁrraga Baldó, M. ${ }^{a}$ Luisa: "El Real Taller de Mármoles de Madrid”. Revista Dolmenhir, Marzo, 2003, Derio. Vizcaya, p. 80. 
es evidente que, en toda esta ornamentación, se aplicó profusamente infinidad de variedades de rocas ornamentales de procedencia española.

\section{DOCUMENTO}

Razon de los Jaspes, y Marmoles que se eligen por mas propios, y convenientes para el adorno, y casamiento de las Piezas publicas del Quarto pral. del nuevo $\mathrm{R}^{\mathrm{l}}$. $\mathrm{Pal}^{\circ}$. cuios generos, y calidades son los mismos que contiene el Arca, y demas que se han descubierto en los dominios de España; y se anotan con los mismos num ${ }^{\text {ros }}$. parages y leguas que expresa su memoria, y con letras alphabeticas los ultimam ${ }^{\text {te }}$. descubiertos; que no estan inclusos en dha. Arca.

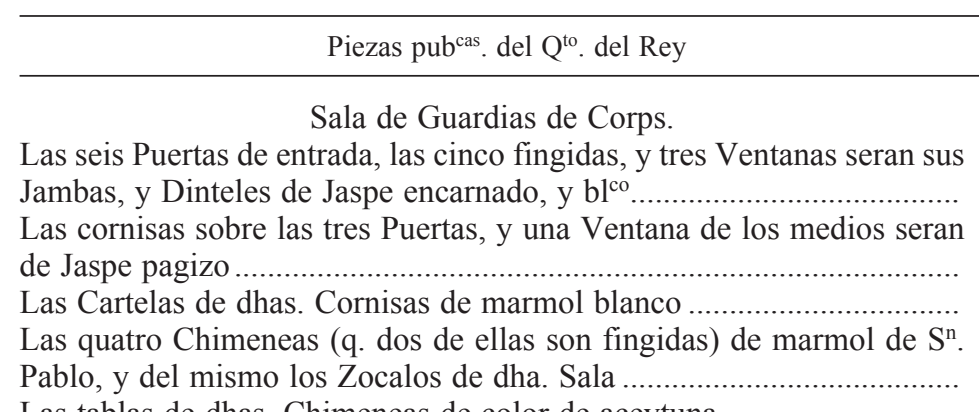

Las tablas de dhas. Chimeneas de color de aceytuna.

Num ${ }^{\text {ro }}$ Parages Leguas

Prim ${ }^{\text {ra }}$. Antecamara.

En quatro Puertas de esta Pieza seran sus Cercos, y Mochetas de Espejon con betas moradas

La parte de afuera contra dhas. molduras Pajizo.

A .... Saceda …...................... 13

C ..... Saceda ........................ 13

Los Cercos de las dos Ventanas del mismo Espejon

Las Jambas y Dinteles de dos Chimeneas de Jaspe de color de Sangre claro con manchas blanc cas

Las tablas y Molduras de Jaspe de Tortosa....

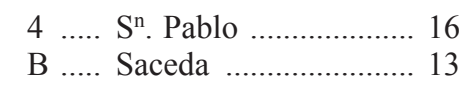

\section{2. ${ }^{\mathrm{a}}$ Antecamara.}

Las Molduras y Mochetas de dos Puertas, de Espejon.

Sus Contramolduras, Jaspe pagizo

Las Mochetas de las dos Ventanas del mismo Espejon

La Chimenea, sus Jambas, y Dintel, Jaspe agatado...

La tabla y Molduras, Marmol negro.

\section{3. ${ }^{\text {a }}$ Antecamara}

Dos Puertas, y tres Ventanas como las de la 2. ${ }^{\mathrm{a}}$ Antecamara

Las Jambas, y Dintel de la Chimenea, color de Caña con mancha negra. La tabla y Molduras, color de Melocoton.

\section{Salon de Besa Manos}

Basa, y Cimacios del Pedestal ó Rodapie, pagizo.

$34 \quad \ldots \mathrm{S}^{\mathrm{n}}$. Ger ${ }^{\mathrm{mo}}$. de Espeja .. 30

E ..... Saceda ........................ 13

G .... Saceda ...................... 13

$58 \ldots$ Tortosa ..................... 80

$34 \quad \ldots . \mathrm{S}^{\mathrm{n}}$. Ger ${ }^{\mathrm{mo}}$. de Espeja .. 30

E ..... Saceda ....................... 13

52 ... Naquera ..................... 50

4 .... $\mathrm{S}^{\mathrm{n}}$. Pablo .................. 16

Neto de dho. Rodapie, y Mochetas de Arcos, Jaspe color de rosa seca con manchas blancas

55 ... Tudela ....................... 40

24 ... Saceda ...................... 15

$60 \quad$... Alcadrete ................. 18

10 ... Siguenza ................... 25

13 ... Granada .................... 60

28 ... Borja ......................... 50

60 ... Alcadrete ................... 18

$13 \ldots$ Gran $^{\mathrm{da}}$...................... 60

Arquitrave y

Molduras, y Mochetas de las cinco Puertas, y cinco Ventanas, de Espejon.......

34 ... Sn. Germo. de Espeja .. 30 


\begin{tabular}{llll}
\hline Piezas pub $^{\text {cas }}$. del $Q^{\text {to }}$. del Rey & Num $^{\text {ro }}$. & Parages & Leguas \\
\hline
\end{tabular}

Las fajas de dhas. Puertas y Ventanas contra las Molduras, vetas blancas y encarnada.

Requadro, berde 60

Tambanillos, pagizo con manchas blancas ..................................

Cornisa de dhas. Puertas, Pajizo

13 ... Granada ..................... 60

Las Cartelas de dos Chimeneas de Espejon

Cerco del Hogar, color de Caña con manchas negras

28 ... Borja ........................... 50

$60 \ldots$ Alcadrete ..................... 18

Tablas de dhas. Chimeneas, y sus tacetas, amarillo

$34 \ldots \mathrm{S}^{\mathrm{n}} \cdot \mathrm{Ger}^{\mathrm{mo}}$. de Espeja. .30

55 ... Tudela ........................ 40

Contramoldura de los Espejos, vetas blancas, y encarnadas.....

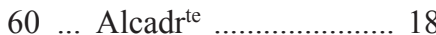

Cornisas, pagizo ............................................................................

Los ocho Nichos sobre las dos Puertas y dos Chimeneas, de marmol

blanco, y los adornos de bronce.

Salon de funciones.

Los Zocalos, Arquitrave, y Corona de la Cornisa, almendrado

Vaciados, Encarnado claro

41 ... Pamplona .................... 60

$60 \quad$... Alcadr ${ }^{\text {te }}$....................... 18

Contra molduras de los Espejos, Encarn ${ }^{\mathrm{do}}$. con manchas blancas, y de la misma las Molduras, y Mochetas de las Puertas .................................. Cornisas de Puertas, y Chimeneas, y fajas de Entre Pilastras, pagizo... Tacetas de las 10 Puertas, sus Mascaras; Marmol blanco

Las Cartelas, y Dintel de las Chimeneas, Encarn ${ }^{\mathrm{do}}$. bajo

Sala particular del Rey

Las Molduras, y Mochetas de sus dos Puertas, de Espejon

Las Contra Molduras, Jaspe pagizo

Mochetas de las dos Ventanas del mismo Espejon ..................................

Chimenea, del mismo....

Su tabla, Encarn ${ }^{\text {do }}$. vetas blancas.

D .... Saceda ........................ 13

$31 \quad$... Saceda ........................ 15

FF ... Saceda ...................... 13

E ..... Saceda ....................... 13

$14 \ldots$ Naque $^{\mathrm{ra}}$..................... 50

$34 \quad \ldots \mathrm{S}^{\mathrm{n}}$. Germo . de Espeja .. 30

E ..... Saceda ........................ 13

63 ... Lerida 75

Piezas pub ${ }^{\text {cas }}$. del $\mathrm{Q}^{\text {to }}$. de la Reyna.

Sala de Guards. de Corps

$\mathrm{Mol}^{\text {ra }}$. y Mochetas de las dos Puertas, Encarn ${ }^{\mathrm{do}}$. vetas blancas.

Mochetas, y Dinteles de las tres Ventanas, de la misma...

Jambas, y Dintel de la Chimenea, Marmol Negro, y blanco.

FF ... Saceda

$4 \quad \ldots . . \mathrm{S}^{\mathrm{n}}$. Pablo $\ldots \ldots \ldots \ldots \ldots \ldots \ldots . . . . . .16$

\section{Antecamara}

Las Molduras, y Mochetas de las Quatro Puertas, Encarn ${ }^{\text {do }}$. con vetas blancas......

Los cercos de las tres Vent ${ }^{\text {nas }}$. de la misma...

Las Contra Molduras de las Puertas; blanco; de vetas Encarndas ............

Las Jambas y Dintel de la Chimenea, almendrado

$$
\text { 1. }{ }^{\text {a Sala del }} \mathrm{Q}^{\mathrm{t}} \text {. familiar. }
$$

Jambas y Dinteles de las seis Puertas, y Cercos de las tres Ventanas de Espejon.

Las Contramolduras de dhas. Puertas, $\mathrm{bl}^{\mathrm{co}}$. vetas Encarnadas

Las Cornisas de dhas. Puertas, pagizo.

34 ... Sn. Germo. de Espeja .. 30

19 ... Alcadrete ................... 18

E ..... Saceda ......................... 13

Las Moldras. del Cerco de la Chimenea, de la misma.

55 ... Tudela ........................ 40

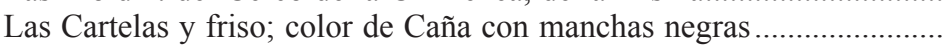

La tabla, agatado.

26 ... Leon 


\begin{tabular}{clll}
\hline Piezas pub $^{\text {cas }}$. del $Q^{\text {to }}$. del Rey & Num $^{\text {ro }}$. & Parages & Leguas \\
\hline 2. ${ }^{\text {a }}$ Sala. &
\end{tabular}

Las 6 puertas, y los dos Cercos de Ventanas, como la 1. ${ }^{\text {a Sala }}$

Las Molduras de los Cercos de las Chimeneas, amarillo...

E ..... Saceda ..................... 13

Sus Cartelas, y friso, verde.

13 ... Granada ..................... 60

La tabla, Encarnado bajo con vetas agatadas.

14 ... Naquera .................... 50

$$
\text { 2. }{ }^{\text {a }} \text { Antecam }{ }^{\text {ra }} \text {. de } Q^{\text {to }} \text {. partic }{ }^{\text {lar }} \text {. }
$$

Las 4 Puertas, y las dos Ventanas como las de la 1. a Antecamara.

Jambas, y Dintel de la Chimeneas, Encarn ${ }^{\text {do }}$. almendrado...

11 ... Villamayr

Otra Sala

Las 4 Puertas, y las 2 Ventan $^{\mathrm{s}}$. como la anteced ${ }^{\mathrm{te}}$. Antecam ${ }^{\mathrm{ra}}$.

Galería.

Jamba, y Mochetas de 10 Puertas, de Espejon

Cercos, y Mochetas de 6 Ventanas, y faxas de los requadros Jaspe

blanco, y Encarn ${ }^{\mathrm{do}}$......

Contramold $^{\text {ras }}$. de las Puertas, y remenatos, pagizo

34 ... Sn. Germo. de Espeja .. 30

Debajo de dhos. remen ${ }^{\text {tos }}$. verde

41 ... Pamplona ................... 60

E ..... Saceda ..................... 13

13 ... Granada ..................... 60

Fondo de Puertas, Color de rata ................................................... 39 ... Alborton .................. 55

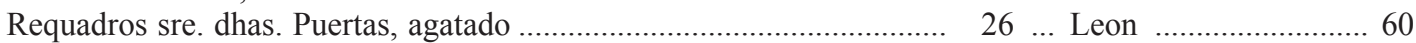

Zocalo, y faja de Pedest ${ }^{\text {les }}$. pajizo........................................................ E ..... Saceda ..................... 13

Vivo del Pedestal, azulado, y blanca ................................................ $36 \quad \ldots$ Leon ........................ 60

Fondos de sus Requadros, y cercos de Chimen's de Brocatelo ............ 58 ... Tortosa ..................... 80

Tabla de dhas. Chimeneas, verde .................................................. 13 ... Granada ................... 60

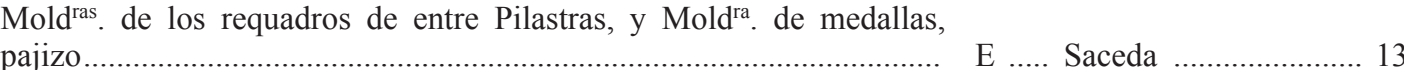

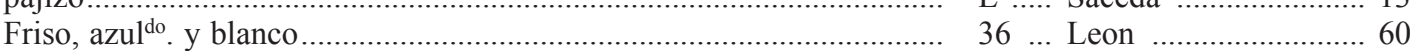

Las Vasas, Capiteles, y tropheos seran de Marmol blanco de Granada, ó Badajoz.

Las Medallas de los Retratos de la Familia $\mathrm{R}^{1}$. en bajos relieves, de Marmol blanco de Carara.

Assimismo las Pilastras de dha. Galeria, dorado con manchas blancas, y agatado

$28 \ldots$ Borja ........................ 50

Arquitrave, y Cornisa, pagizo.............................................................. E ..... Saceda ....................... 13

No ba el Casamento, que corresponde á la Capilla, hasta que S. M. se digne resolver la eleccion de las ideas, que tengo presentadas, y se me entregue el Dibujo, sin el qual no puedo hacer dho. casamento. Mad ${ }^{\mathrm{d}}$. 3 de Agosto de 1749.

(firma) D. Juan Batp ${ }^{\text {ta }}$. Saqueti.

Fecha de recepción: 10-II-2009

Fecha de aceptación: 15-VI-2009 